\section{Intersections}

Canadian Journal of Music

Revue canadienne de musique
Intersections CANADIAN TOURALL OR MUSIC

\title{
Poésie et musique : L'Horizon chimérique, de Jean de la Ville de Mirmont à Gabriel Fauré
}

\section{Jean Molino}

Volume 31, numéro 1, 2010

URI : https://id.erudit.org/iderudit/1009288ar

DOI : https://doi.org/10.7202/1009288ar

Aller au sommaire du numéro

Éditeur(s)

Canadian University Music Society / Société de musique des universités canadiennes

ISSN

1911-0146 (imprimé)

1918-512X (numérique)

Découvrir la revue

Citer cet article

Molino, J. (2010). Poésie et musique : L'Horizon chimérique, de Jean de la Ville de Mirmont à Gabriel Fauré. Intersections, 31(1), 100-162.

https://doi.org/10.7202/1009288ar
Résumé de l'article

Dans cet article, l'auteur retrace la genèse de L'Horizon chimérique de Fauré, depuis sa première rencontre entre le musicien et le poète jusqu'au terme de la mise en musique et finalement le problème de l'exécution. Il attache une importance particulière aux caractéristiques formelles du poème (prosodie, rythme, métrique) et essaie de montrer l'importance qu'elles revêtent tout au long du parcours créateur jusqu'aux plus petits détails de la mise en musique.
All Rights Reserved ( C Canadian University Music Society / Société de musique des universités canadiennes, 2012
Ce document est protégé par la loi sur le droit d'auteur. L'utilisation des services d'Érudit (y compris la reproduction) est assujettie à sa politique d'utilisation que vous pouvez consulter en ligne.

https://apropos.erudit.org/fr/usagers/politique-dutilisation/ 


\title{
POÉSIE ET MUSIQUE: L'HORIZON CHIMÉRIQUE, DE JEAN DE LA VILLE DE MIRMONT À GABRIEL FAURÉ
}

\author{
Jean Molino
}

\section{INTRODUCTION}

Je m'intéresse dans ce travail aux relations entre poésie et musique dans le dernier recueil de mélodies de Fauré, L'Horizon chimérique. Il se situe donc au point de rencontre de trois directions de recherche. Il s'agit d'un côté des progrès faits dans la connaissance de Fauré. Il ne faut pas oublier que la réhabilitation du musicien est assez récente : on peut la dater de la publication de la première édition du Fauré de Jean-Michel Nectoux dans la collection «Solfège» en 1972 (Nectoux 1972). C'est le travail exceptionnel de ce chercheur qui a véritablement renouvelé la connaissance du compositeur et l'a fait enfin accéder à l'âge du savoir «serein» et objectif. Son livre de 1990, Gabriel Fauré, les voix du clair-obscur, m'a constamment servi de guide (Nectoux 1990; $2^{\text {ème }}$ édition 2008). Je voudrais aussi rappeler le remarquable ouvrage de Frits Noske, publié en français en 1954, La Mélodie française de Berlioz à Duparc : essai de critique historique, ouvrage pillé plus que cité et dont la seule réédition est en anglais chez Dover (Noske 1970), ainsi que l'important travail analy tique réalisé par tant de musicologues anglophones, du Gabriel Fauré de Robert Orledge (Orledge 1979; édition révisée 1983) à la thèse que Robin Tait a consacrée au langage musical de Fauré (Tait 1989). Si Jean-Michel Nectoux n'hésitait pas à écrire dans son livre de 1990 que «la recherche sur l'œuvre de Gabriel Fauré ne fait que commencer», la toute récente deuxième édition de son ouvrage manifeste abondamment que «la recherche sur le musicien a pris un véritable essor sur le plan international» (Nectoux 2008, p. 16).

Il s’agit par ailleurs des recherches portant sur les relations de la poésie et de la musique. En France, elles ont surtout porté sur les XVI-XVII e siècles à partir de l'article fondateur de Jean-Pierre Ouvrard (Ouvrard 1981; His 1993, 1998, 2006; Bettens 2008). Les travaux concernant le XIX ${ }^{\mathrm{e}}$ et la mélodie française ont été beaucoup plus rares en dehors de l'important développement consacré à ces problèmes dans l'ouvrage déjà cité de Noske (Noske 1970, p. 36-61: «Esquisse historique de la théorie prosodique»). Il s’agit enfin du véritable renouvellement qu'a connu l'étude de la versification française depuis les années 1970, sous l'influence des méthodes de la linguistique générative (Gouvard 1999 et 2000; Beaudouin 2002, p. 25-57). Citons en particulier les travaux de Jacques Roubaud (notamment, La Vieillesse d'Alexandre (Roubaud 1978) et Benoît de Cornulier (Cornulier 1982 et 1995) sans oublier le monumental ouvrage, bien 
antérieur, de Georges Lote, qui fait appel à plusieurs reprises au témoignage de la musique pour reconstituer les différentes modalités et l'évolution de la diction des vers (Lote 1949-1996, tomes 1-9).

D’une façon générale, il n'est pas sûr que, à cause en particulier de la division du travail entre musicologues et spécialistes de poésie, on accorde assez d'importance aux questions de versification dans l'analyse de la parole chantée. Lorsque Rousseau se livre à l'analyse du monologue d'Armide dans l'opéra de Lully, il reproche au musicien d'avoir placé un trille sur une "syllabe brève" du mot «invincible» (Rousseau [1753] 1995, p. 324), et Rameau lui fait justement remarquer qu'il commet alors une erreur de prosodie : «C'est bien ignorer et bien peu sentir notre prosodie, que d'y taxer de brève la dernière syllabe masculine d'un mot, lorsqu'il n'y en a pas une qui n'y soit longue. Il ne faut pas s'étonner, après cela, des conséquences que l'on en tire pour notre récitatif» (Rameau [1754] 1980, p. 179). Rousseau ne comprend pas que, pour Lully, la recherche de l'expressivité ne peut se manifester que dans le cadre des conventions d'une diction avant tout soumise aux deux accents de la césure et de la rime : «On trouve dans les opéras de Lully des steppes de récitatifs et d'airs, où le premier temps de chaque mesure tombe avec une raideur implacable sur la rime, ou sur la césure de l'hexamètre. C'est d'une monotonie accablante» (Romain Rolland, cité dans Lote 1949-1996, tome 6, 366). Ce commentaire de Romain Rolland est d'autant plus significatif qu'il annonce les jugements que l'on portera, au $\mathrm{XX}^{\mathrm{e}}$ siècle, sur un Fauré «victime d'une acceptation trop passive du mètre verbal» (Beaufils [1954] 1994, p. 135).

Quant à la méthode, je m'inscris dans le cadre de l'individualisme méthodologique (Laurent, 1994) ${ }^{1}$ et plus particulièrement de ce que Karl Popper a appelé logique ou analyse de situation (Popper 1957, dans 1956, p. 145-157; 1972, p. 178-179). Il s'agit de se livrer, de façon hypothétique mais validable, à une reconstruction idéalisée des étapes du travail créateur du musicien : la rencontre avec un poète, le traitement qu'il fait subir à ses poèmes, la façon dont il les «met en musique», en essayant de préciser à chaque étape le rôle que jouent les structures poétiques dans l'élaboration de la mélodie.

\section{LA RenContre entre Pồte ET MUSicien : JeAN de LA Ville DE MIRMONT (1886-1914) ET L'HoRIZON CHIMÉRIQUE}

L'Horizon chimérique op. 118, composé en 1921 après l'achèvement de la Deuxième sonate pour violoncelle et piano op. 117, est dédié au jeune baryton suisse Charles Panzéra (1896-1976), qui le crée à la Société nationale de musique le 13 mai 1922, le lendemain du soixante dix-septième anniversaire du musicien. Il n'écrira plus que le $13^{\mathrm{e}}$ Nocturne pour piano en si mineur op. 119, le Trio pour piano, violon et violoncelle en ré mineur op. 120 et le Quatuor à cordes en mi mineur op. 121 avant de mourir le 4 novembre 1924.

La composition d'un lied ou d'une mélodie est le résultat de la rencontre entre un poète et un musicien et, si l'on demandait au musicien pourquoi il a

1 Pour une application des principes de ce courant à la socio-histoire de la musique, cf. Jean Molino, Le Singe musicien. Sémiologie et anthropologie de la musique 2009, p. 269-275. 
choisi tel poème, il répondrait sans doute, comme Montaigne parlant de son amitié avec La Boétie : «Parce que c'était lui, parce que c'était moi». On pourrait évidemment s'intéresser au poète et se livrer à son sujet, comme dirait Jean-Jacques Nattiez, à une espèce d'enquête policière (Nattiez 2007, p. 31) : qui était-il ? qu’a-t-il écrit? où se situe son œuvre dans la littérature française du début du XX ${ }^{\mathrm{e}}$ siècle? Cette enquête serait d'autant plus intéressante que sa personnalité et son œuvre, telles qu'on peut en deviner quelques contours à partir de ses minces Euvres complètes, publiées seulement en 1992 (La Ville de Mirmont 1992), ont quelque chose d'énigmatique et de fascinant. Mais toute enquête historique ou philologique entraîne des prolongements infinis et, comme l'analyse selon Freud, est interminable. C'est pourquoi il faut se limiter. Essayons de nous mettre dans la situation de Fauré telle qu'on peut tenter de la reconstituer : il a lu le recueil de poèmes de Jean de la Ville de Mirmont parce qu'il en avait entendu parler ou l'avait découvert lui-même, mais il ne connaissait sans doute pas beaucoup plus de l'auteur que ce que l'on pouvait savoir et dire de lui en 1920, au moment où paraît l'édition posthume de L'Horizon chimérique. Aux mérites intrinsèques de l'œuvre s'ajoutait certainement le pathétique du poète mort jeune, auquel on peut penser que le vieux Fauré était particulièrement sensible, plus certainement que le vieux Mauriac qui, évoquant l'ombre de son ancien ami Jean de la Ville de Mirmont, n’a pas hésité à écrire, avec la méchanceté chrétienne qui le caractérisait :

Pour lui qui avait vingt-cinq ans, comme pour Charles Péguy qui en avait quarante, c'est un fait que la guerre fut une délivrance. Oui, ce qu'il y a de plus horrible au monde, des millions de jeunes hommes qui s'entretuent, il dut y voir le point final mis par le destin à une vie besogneuse et sans issue et qui lui donnait tout à coup une signification héroïque. [...] et moi, après tant d'années, je songe que c'est elle, la mort, qui me l'a rendu, lui et tant d'autres que, s'ils étaient devenus des vieillards aujourd'hui, je ne connaîtrais plus ou dont je redouterais la visite.» (Mauriac, dans La Ville de Mirmont 1992, p. 53)

Que trouve-t-on dans le recueil? [Annexe 1]. L'Horizon chimérique constitue la première section du volume publié en 1920 sous le même titre général (La Ville de Mirmont 1920) et a sans doute été écrit en 1911-1912. Il s'agit d'une suite de 14 poèmes qui ont entre huit et seize vers et sont constitués dans leur très grande majorité de deux, trois ou quatre quatrains ${ }^{2}$. Ils sont écrits en alexandrins et respectent à une exception près l'alternance des rimes masculines et féminines.

Il ne faut évidemment pas exagérer la cohérence du recueil, mais on peut tenter de dégager le sens global des 14 poèmes qui le constituent. On y trouve le vieux thème baudelairien et mallarméen de l'ennui, auquel est consacré le poème VI. S’adressant aux vaisseaux, il leur déclare :

Sur votre proue et dans mes yeux il est écrit

2 La seule exception dans les poèmes retenus par Fauré est la première strophe du poème XIVdevenu II dans le cycle de mélodies - qui comprend cinq vers («Je me suis embarqué ... »). 
Que l'ennui restera notre vieux camarade.

Il y a en contrepoint le thème des "désirs nomades», le désir des voyages, de l'exotisme et de l'ailleurs que l'on retrouve chez un certain nombre de poètes appartenant à la même génération que Jean de la Ville de Mirmont, né en 1886 : Jean-Marie Levet, né en 1874; Victor Segalen, né en 1878; Valéry Larbaud, né en 1881; Carco, né en 1886; Cendrars, né en 1887; Saint John Perse, né en 1887 ou Morand, né en 1888. Mais, à la différence de ces voyageurs, le poète ne part pas. S'il entend, du fond de son ennui, l'appel qu'entendait Mallarmé dans son poème de 1865, «Brise marine», («Mais, ô mon cœur, entends le chant des matelots!»), il ne se décide pas à partir, d'où le caractère un peu surprenant du dernier poème du recueil dans lequel il proclame : «Je me suis embarqué ... ».

En fait, ce qui constitue la tonalité la plus personnelle du recueil, c'est, d'une part, la présence physique non de l'ailleurs mais du port et de la mer, et de l'autre la tension entre l'envie de départ et l'incapacité de partir. On sent dans ses vers le «Souffle humide d'embrun et brûlant de salure» (Poème VII) ainsi que la réalité vécue du port de Bordeaux :

Je suis né dans un port et depuis mon enfance

J'ai vu passer par là des pays bien divers.

Attentif à la brise et toujours en partance,

Mon cœur n’a jamais pris le chemin de la mer.

Mais les deux derniers vers de la strophe que je viens de citer et qui ouvre le recueil montrent bien que le poète ne partira jamais. C'est cette contradiction entre les désirs de départ qu'éveille le port et l'impossibilité de partir que reprend la dernière strophe du premier poème et qui domine l'ensemble du recueil :

Les ports ont un parfum dangereux pour les hommes

Et si mon cœur est faible et las devant l'effort,

S'il préfère dormir dans de lointains arômes,

Mon Dieu, vous le vouliez, je suis né dans un port.

Ajoutons un détail qui pourrait aider à préciser l'origine du si beau titre du recueil, L'Horizon chimérique. La chimère est un thème poétique courant dans la deuxième moitié du XIX ${ }^{\mathrm{e}}$ siècle, comme en témoigne le poème de Baudelaire «Chacun sa chimère», dans lequel se trouve le mot «horizon» (Baudelaire 1975, p. 282-283). Il existe par ailleurs au jardin public de Bordeaux une sculpture «Jeunesse et chimère» du sculpteur Pierre Granet (1843-1910). C’est Michel Suffran, le principal artisan de la redécouverte de Jean de la Ville de Mirmont, qui a suggéré le rapprochement en publiant la photographie du groupe dans le volume de la collection «Poètes d'aujourd'hui» qui lui est consacré (Suffran 1968, p. 65) [Annexe 2].

\section{FAURÉ ET LA POÉSIE}

Pourquoi Fauré a-t-il décidé de mettre en musique quelques poèmes du recueil de Jean de la Ville de Mirmont? C'est bien évidemment parce qu'ils lui plaisaient et qu'ils éveillaient en lui le désir de les mettre en musique. En général, 
on ne s'intéresse guère aux préférences littéraires des musiciens qui mettent en musique des poèmes, sinon pour déplorer leur mauvais goût ou, plus rarement, louer leur clairvoyance. Il suffit de songer à ce qu'on dit et écrit couramment au sujet de nombreux cycles de Schubert : pourquoi diable le musicien est-il allé chercher les poésies du médiocre Wilhelm Müller pour composer La Belle Meunière ou Le Voyage d'hiver? Dans le cas de Fauré, il est entendu qu'il avait mauvais goût. Voici ce qu'écrivait à ce sujet l'auteur d'une thèse par ailleurs fort intéressante consacrée aux mélodies de Fauré : «En écrivant ce bref aperçu historique des relations de Fauré avec ses poètes, nous constatons la différence de qualité qui distingue ceux-ci : le meilleur et le pire se côtoient. L'explication réside en partie dans le manque de discernement du musicien qui, bien que parfaitement sensible et intelligent, n'avait pas reçu des bons Pères une formation littéraire à la hauteur de son génie. Par ailleurs, le jugement du temps n'avait pas encore fait son œuvre, il était difficile à un esprit peu critique d'établir en ce domaine une hiérarchie correcte» (Beltrando-Patier 1981, p. 151). Et souvent on l'oppose, sur ce point comme sur bien d'autres, à Debussy (nous aurons l'occasion, à plusieurs reprises, de revenir sur ce parallèle plus ou moins explicite).

Laissons répondre Charles Kœchlin, disciple de Fauré : «On se figure aussi, dans certains milieux, que les compositeurs sont des incultes, choisissant d'instinct les poésies médiocres. Erreur profonde : sauf de rares exceptions, les meilleurs musiciens ont toujours préféré les meilleurs poètes, et cela pour le plus grand bien de leurs œuvres» (Kochlin 1925, II, p. 2). Le musicien qui compose une mélodie sur un texte qu'il a choisi est un homme qui s'intéresse à la littérature et qui aime la poésie. Il y a, en effet, une grande différence avec ce qui se passe dans le choix d'un livret d'opéra. Pour un opéra, le musicien s'intéresse plus aux situations et aux personnages qu'à la littéralité du texte. En revanche, quand il s'agit d'un lied ou d'une mélodie, c'est le texte qui importe, et cela d'autant plus pour un musicien comme Fauré qui était très sensible aux qualités littéraires des poèmes qu'il choisissait pour les mettre en musique.

Pour comprendre le choix de Fauré, il faut évidemment se débarrasser des présupposés qui apparaissent dans le texte que nous avons cité. Le plus important de ces présupposés est qu'il existe un seul bon goût, auquel tous les bons esprits ont dû et doivent obéir, et que ce bon goût correspond providentiellement au consensus officiel de la génération à laquelle on appartient : les bons, les grands poètes, comme les grands musiciens, ne peuvent être que ceux qu'on reconnaît aujourd'hui comme tels. Or l'histoire ne cesse jamais de se réécrire et les grands poètes ou musiciens d'aujourd'hui ne sont pas toujours ceux que l'on célébrait hier (Molino 2006). Il n'y a pas, par ailleurs, à un moment donné «un» état de la poésie ou du goût poétique, pas plus qu'il n'y a «un» état de la musique et du goût musical, mais plusieurs groupes distincts de créateurs et d'amateurs. C'est à cette diversité que fait allusion le musicologue allemand Carl Dahlhaus lorsqu'il parle de la «non-contemporanéité du contemporain»: on publie autour de 1920, au moment où paraît L'Horizon chimérique, des livres de poésie aussi différents que Calligrammes d'Apollinaire et le Manifeste Dada 
1918 de Tzara, tous deux en 1918, en 1921 Le Laboratoire central de Max Jacob et en 1922 Charmes de Valéry ...

Chacun enfin - amateur, poète ou musicien -, s'inscrit dans une trajectoire individuelle. Il faut donc, en se fondant sur les principes de l'individualisme méthodologique, situer le choix de Fauré dans l'évolution de ses goûts, dans lesquels interviennent, outre sa personnalité, la génération à laquelle il appartient et les groupes auxquels il se rattache. Parmi les poètes de sa génération - il est né en 1845 - figurent Verlaine (1844), Sully Prudhomme (1839), Armand Silvestre (1837), Villiers de l'Isle Adam (1838), qu'il a mis en musique, mais aussi Mallarmé (1842), Charles Cros (1842) ou Corbière (1845), qu'il a ignorés. Il a certainement aussi subi l'influence des milieux qu'il a fréquentés, ces milieux mondains et aristocratiques dans lesquels Proust a fait tant d'efforts pour entrer et auxquels, grâce à Niedermeyer, à Saint-Saëns et aux Viardot, le fils d'instituteur Fauré a très tôt accédé sans le rechercher.

On peut approximativement distinguer quatre périodes dans l'évolution de ses goûts poétiques (Beltrando-Patier 1981, p. 137-185; Nectoux 2008, p. 237240). Une première période correspond à sa formation. Suivant l'exemple de son maître Niedermeyer qui avait mis en musique Le Lac (1825) et L'Automne de Lamartine, Fauré s’adresse pour ses premières mélodies aux poètes les plus connus de son époque, Hugo - une des grandes admirations de son maître et ami Saint-Saëns-, Gautier et Baudelaire. Il passe ensuite à des poètes appartenant à sa génération, Sully Prudhomme - qui recevra en 1901 le Prix Nobel de Littérature - et Armand Silvestre, dont l'œuvre est au centre d'une deuxième période, qui va à peu près de 1878 à 1884 . Avec ce poète bien oublié aujourd'hui qui occupe une place importante dans le deuxième recueil de mélodies de Fauré commencent à se préciser les goûts poétiques du musicien. Une troisième période s'ouvre sous l'influence du comte de Montesquiou-Fezensac, le modèle du Des Esseintes de Huysmans, que Fauré rencontre en 1886 et qui lui sert de véritable «conseiller littéraire» (Nectoux 2008, p. 238). C’est lui qui lui révèle Verlaine et, de 1887 à 1894, Fauré met en musique 18 de ses poèmes, dont les 9 qui constituent le cycle de La Bonne Chanson (1892-1894). C'est alors le moment du symbolisme - le Manifeste du symbolisme de Moréas date de 1886 - et Fauré met en musique quelques poèmes d'Albert Samain ou d'Henri de Régnier. Une quatrième et dernière période correspond à l'époque où Fauré, continuant sur la voie dans laquelle il s'était engagé avec La Bonne Chanson, procède par cycles consacrés à un même poète. En 1906, il découvre le poète symboliste belge Charles Van Lerberghe, à qui il emprunte les textes de $L a$ Chanson d'Eve (1906) puis du Jardin clos (1914). Les poèmes du cycle suivant, Mirages (1919), sont pris dans le recueil du même titre de la baronne Renée de Brimont et c'est enfin à Jean de la Ville de Mirmont qu'il s'adresse pour son dernier cycle, L'Horizon chimérique (1921).

Il faut ajouter que, dès les années 1880, cette période si riche pour la poésie française, Fauré est devenu, comme le dit Jean-Michel Nectoux, «un lecteur assidu de poésie» : «Outre les recueils, nombreux, qu'il se procure, Fauré parcourt assidûment la presse et les revues où les publications de poèmes abondent» (Nectoux 2008, p. 452). Il est constamment à la recherche de poésies à 
mettre en musique et il se plaint de ne pas en trouver qui lui conviennent. Voici ce qu'il écrit dans une lettre à une amie :

Je cherche (et je ne les trouve pas) de beaux vers à mettre en musique pour Madame de Saint-Marceaux ! Le nombre de recueils que j'ai parcourus est innombrable. Mais j'y ai trouvé des mots, des mots et peu de pensée. Tout cela est extérieur et la musique n'a rien à y puiser ! Et que de fadaises et de fadeurs! Mme Bartet est venue me voir hier. Elle qui m'avait trouvé Le parfum impérissable ne trouve plus rien non plus. (lettre à Marguerite Baugnies citée dans Nectoux 2008, p. 453)

On pourrait s' interroger sur la «valeur» des poètes mis en musique par Fauré et sur le rang qu'ils occupent dans le «canon" poétique de notre temps - il faut préciser « et de notre milieu». Il est sans doute plus intéressant d'essayer de comprendre ce que Fauré recherchait dans un poème pour le mettre en musique. Il l'a dit lui-même très clairement dans un texte de 1911, en réponse à une enquête de la revue Musica qui avait posé la question "Sous la musique que faut-il mettre ?3». Il explique d'abord, condamnant ainsi ses premières tentatives, pourquoi il n'a «jamais réussi» à «mettre en musique» ni Hugo ni les Parnassiens :

La forme importe beaucoup, mais le fond importe davantage encore. Je n'ai jamais pu mettre en musique des Parnassiens purs, par exemple, parce que leur forme élégante, jolie, sonore, tient tout entière dans le mot et que le mot ne recouvre aucune vraie pensée. Je n'ai jamais réussi non plus à mettre du Victor Hugo en musique, et rarement du Leconte de Lisle, parce que leurs vers à tous deux sont trop pleins, trop riches, trop complets pour que la musique puisse s'y adapter utilement.

L'allusion à Leconte de Lisle va nous permettre de nous rapprocher de ce que Fauré aime ou n'aime pas dans un poème. Il a fait appel à lui de façon discontinue au cours de sa carrière, cinq fois en tout, mais il s'agit chaque fois de quelques-unes des plus belles mélodies du musicien4. Est-ce le résultat d'affinités électives entre poète et musicien? (Vivès dans Faure et Vivès 2000, p. 125-128). Peut-être, mais il faut surtout souligner que Fauré ne s'intéresse qu'à un seul aspect de Leconte de Lisle, non à l'auteur des Poèmes barbares et des Poèmes tragiques, non au chantre d'une Grèce farouche et hiératique, mais à l'auteur d'Odes anacréontiques et au traducteur de Théocrite, au poète qui a célébré le désir, la sensualité, la jeunesse et l'amour de la vie.

Écoutons Lydia, le premier poème de Leconte de Lisle mis en musique par Fauré autour de 1870, qui est sans doute la première mélodie dans laquelle il fait entendre une voix pleinement personnelle : on y entend en particulier le triton caractéristique $f a$-si, qui fait passer de $f a$ majeur au mode de $f a$ (mode lydien). Mais il vaut la peine de comparer au texte de la mélodie le texte du poème, paru dans la première édition des Poèmes antiques (1852) et qui fait

3 Nous citons la réponse de Fauré d'après Nectoux 1995, p. 104.

4 Il s'agit des poèmes et mélodies suivants : Lydia, Nell, Les Roses d'Ispahan, La Rose et Le Parfum impérissable. 
partie d'une section intitulée "Études latines», inspirée des élégiaques latins [Annexe 3]. Fauré apporte plusieurs modifications au poème. D’une part, au vers 8 , il change «sur tes lèvres en fleur» en «sur ta lèvre en fleur». Et d'autre part il transforme les vers 2 et 3 . Au lieu de

Et sur ton col frais et plus blanc

Que le lait, roule étincelant

L'or fluide que tu dénoues.

il corrige

Et sur ton col frais et si blanc

Roule étincelant

L'or fluide que tu dénoues.

Il procède par ailleurs à trois répétitions : aux vers 7 («baisers, baisers de colombe »), 8 («sur ta lèvre en fleur») et 16 («mourir, mourir»).

Quel est le sens de ces modifications? Ne craignons pas ici d'entrer dans l'atelier du musicien, car c'est de ces petits «détails» que sont faites les créations poétiques et musicales. En premier lieu, Fauré est très sensible aux sons du poème, mais, comme il le dit dans le passage que je viens de citer, il n'aime ni la poésie des Parnassiens parce qu'il la trouve trop «sonore», ni les vers de Hugo et de Leconte de Lisle parce qu'ils lui semblent «trop pleins, trop riches, trop complets». De manière générale, il évite les allitérations (Nectoux 2008, p. 448-450). Dans Lydia, il supprime les sonorités qui lui paraissent désagréables : c'est le cas dans le groupe "tes lèvres en fleur", où il supprime la liaison qui, avec le son « $\mathrm{z}$ », est un danger perpétuel pour quelqu'un qui chante. Cette modification lui permet en même temps de remplacer la succession de voyelles de «tes-lè» - un «é» fermé suivi d'un «è» ouvert - par la succession beaucoup plus fluide «ta-lè» - succession des deux voyelles ouvertes «a» et «è» ouvert.

En second lieu, le compositeur qui met un poème en musique entre dans une dialectique d'échanges entre les contraintes propres à chacune des deux formes d'expression. À l'époque de Lydia, il est soumis à deux types de contraintes : l'une qui tire du côté de la poésie en soumettant la musique à la structure strophique, l'autre qui tire du côté de la musique en soumettant les vers au principe de la carrure. La mélodie est organisée en deux «macrostrophes » elles-mêmes composées de deux strophes du poème. À l'intérieur de ces macrostrophes, chaque groupe de deux vers constitue une phrase carrée de quatre mesures. Or le maintien de l'enjambement des vers 2 et 3 ne respecterait plus cette organisation; c'est pourquoi Fauré le supprime, ce qui le conduit à remplacer les mots supprimés du vers 3 par " une incise de piano continuant la phrase mélodique» (Nectoux 2008, p. 462). Quant aux répétitions des vers 8 et 16, elles permettent, en faisant passer la dernière phrase de quatre à cinq mesures, de lui donner une allure conclusive.

En supprimant l'enjambement, Fauré a en même temps fait disparaître la comparaison «plus blanc / Que le lait». Il n'en était sans doute pas mécontent, parce que, de manière générale, il n'aimait ni les comparaisons ni les 
métaphores ni les descriptions trop concrètes (Nectoux 2008, p. 446-447). C'est bien ce qui apparait dans la suite du texte cité, où il explique les raisons de son éloignement de Hugo et Leconte de Lisle :

Les épithètes y sont nombreuses, et, quand la musique les souligne, les épithètes prennent une proportion énorme. Ainsi, "Hélène aux pieds blancs", c'est charmant à dire; cela fait image. Si l'on y ajoutait des notes et que l'on essayât de chanter, ces pieds paraîtraient gigantesques, tout à fait disproportionnés. Ce serait absurde et ridicule. On ne pourrait s'empêcher de sourire.

Quel est alors le poète auquel il fait appel pour préciser les qualités qu'il attend d'un poème pour avoir envie de le mettre en musique? C'est, comme l'indique la suite du texte, Verlaine :

Verlaine est exquis à mettre en musique. Tenez, il y a de lui un court poème, Green, qui contient un paysage frais et mélancolique, mais ce paysage n'est que l'atmosphère, l'ambiance. Et l'harmonie devra s'attacher à souligner le sentiment profond que ne font qu'esquisser les mots. De même, dans «Il pleure dans mon cœur comme il pleut sur la ville ... », le bruit des gouttes d'eau n'est qu'un accessoire. La lamentation amoureuse et inquiète est l'essentiel. Le rôle de la musique est d'ailleurs bien celui-là : mettre en valeur le sentiment profond qui habite l'âme du poète et que les phrases sont impuissantes à rendre avec exactitude.

On aurait tort de croire que la forme poétique est indifférente; la forme musicale la complète heureusement, voilà tout. L'essentiel est de comprendre son poète, de le sentir. Mais il ne faut jamais s'attaquer à un médiocre, car il suffit d'un mot de trop, d'un adjectif mal placé pour faire boiter la plus belle page. Tandis qu'une prose rythmée, si elle est fluide, harmonieuse, pourra servir de thème, merveilleusement.

Les goûts de Fauré ont certainement évolué de ses débuts à 1911, date à laquelle il fait la réponse que je viens de commenter, mais n'y a-t-il pas des traits communs aux poèmes qu'il a choisis après une première période de tâtonnements, c'est-à-dire aux poèmes élégiaques de Leconte de Lisle ainsi qu'à la poésie d'Armand Silvestre, de Verlaine et de Charles Van Lerberghe? Les thèmes qu'il aborde dans ses mélodies sont ceux du lyrisme traditionnel : l'amour, le temps, la nature, les regrets, l'absence et la mort. Il évoque bien la distance entre l'idéal et le réel, entre la terre et les aspirations vers "de grands départs inassouvis", mais sans rien du pathos romantique ou du décadentisme fin de siècle. Il s'agit d'un lyrisme presque banal qui, au-delà du lyrisme parnassien et romantique, s'inscrit dans une tradition plus ancienne, la tradition de l'élégie antique. Le poème Lydia fait partie, comme je l'ai déjà signalé, de la section des Poèmes antiques intitulée "Études latines» et se terminait, dans les premières éditions du recueil, par la mention «imité de Gallus», c'est-à-dire du poète latin Cornelius Gallus. Ce que recherche Fauré, c'est un lyrisme modéré aussi bien dans les sentiments que dans la forme, qui refuse les éclats et les ruptures de ton, un lyrisme horatien qui reste fidèle aux deux qualités d'un art classique 
au sens large du mot, le «rien de trop» et l'«aptum», que je préfère traduire par «l'à propos» (Kœechlin 1927, p. 188) plutôt que par «les bienséances». Charles Kochlin, auteur d'un très beau livre consacré à son maître, a justement parlé de la «netteté athénienne» de son art (Kochlin 1927, p. 203). Et ce sont ces mêmes qualités que Fauré retrouve dans le recueil de Jean de la Ville de Mirmont, fils d'un professeur de littérature latine à l'Université de Bordeaux. Ce qu'il a aimé et choisi dans le symbolisme, ce n'est ni le flou ni la langueur ou la préciosité, mais l'expression sans pathétique d'un sentiment profond. En poésie comme en musique, Fauré est un indépendant qui a suivi sa propre voie à l'écart des écoles et des modes.

On voit à quel point les goûts littéraires de Fauré diffèrent de ceux de Debussy, qui appartient à une autre génération - il est né en 1862, soit quinze ans après Fauré - et surtout sans doute à un autre milieu, un milieu d'artistes et littérateurs d'avant-garde. Il est d'autant plus intéressant de souligner leur accord, au moins théorique, en ce qui concerne la conception des rapports entre musique et poésie. Les phrases de Fauré que je viens de lire au sujet des relations entre musique et poésie ne sont pas tellement éloignées, au moins sur le plan théorique, de ce que disait Debussy de leur relation dans le domaine de l'opéra :

Je conçois une force dramatique autre : la musique qui commence là où la parole est impuissante à exprimer; la musique est faite pour l'inexprimable; je voudrais qu'elle eût l'air de sortir de l'ombre et que, par instant, elle y rentrât; que toujours elle fût discrète personne (cité dans Wenck 1976, p. 3).

\section{FAURÉ « S'APPROPRIE » L'HORIZON CHIMÉRIQUE}

Fauré a donc lu le recueil de Jean de la Ville de Mirmont et ces vers ont éveillé en lui un écho, ce qui constitue le premier moment de la création. Fauré ne compose une mélodie que si, à la lecture du poème, il en ressent la nécessité. Voici comment il explique à Robert de Montesquiou, qui lui avait fait connaître un poème de Marceline Desbordes-Valmore, Les Cloches du soir, pourquoi il ne le met pas en musique : «Je n'ai rien composé sur Les Cloches du soir, mais ce qui est plus grave et bien fâcheux pour moi, je ne trouve rien à ajouter musicalement au danger qui rôde? J'en suis désolé et j'y renonce car je n'ai rien ressenti d'avant-coureur! Cela n'est pas venu et ne viendra pas!» (Lettre à Robert de Montesquiou du 24 avril 1896, dans Fauré 1980, p. 198).

Lorsqu'un musicien est en face d'un recueil qu'il songe à mettre en musique, il se livre à un travail de sélection. C'est ce que fait Schubert lorsqu'il choisit 20 poèmes dans les 25 textes du recueil de Wilhelm Müller, La Belle Meunière (Die schöne Müllerin, D 795). C'est de la même façon que procède Schumann lorsqu'il retient vingt poèmes du Lyrisches Intermezzo de Heine pour en faire Les Amours du poète (Dichterliebe, op. 48). Les transformations que le musicien fait subir au recueil doivent être prises plus au sérieux qu'on ne le fait d'ordinaire, car elles témoignent du travail qu'il opère sur le texte et ce travail nous révèle quelque chose du sens qu'il veut donner au texte ainsi modifié et donc, 
d'une façon indirecte, de ses intentions musicales. Je voudrais donc me livrer maintenant à un petit exercice qui mêle ce que Jean-Jacques Nattiez appelle «poḯtique inductive» et "poïétique externe» (Nattiez 1987, p. 177). On part du «niveau neutre», ici le texte des mélodies de Fauré et on le compare au texte du recueil de Jean de la Ville de Mirmont pour tirer de cette confrontation quelques hypothèses sur le sens partiellement nouveau que Fauré voulait donner à son propre cycle [Annexe 4].

Quelles sont donc les modifications que Fauré apporte au recueil original? Il ne retient que quatre des quatorze poèmes, les poèmes numérotés $\mathrm{V}, \mathrm{XI}$, XIII et XIV et les dispose dans l'ordre suivant : XIV devient II, XIII devient I, XI devient III et V devient IV. Par ailleurs, il supprime la dernière strophe du poème XIV devenu II et il faut bien reconnaître qu'elle n'est pas réussie ni en accord avec le reste du poème qu'elle dépare et elle constituait certainement pour Fauré une «faute de goût» (Nectoux 2008, p. 447). Quel sens prennent alors les quatre poèmes ainsi choisis et ordonnés? Le dernier poème du recueil, dont j'ai tout à l'heure souligné l'étrangeté, vient maintenant en deuxième place et, amputé de sa dernière strophe, il évoque moins l'aventure que les regrets du départ («Ô ma peine, ma peine, où vous ai-je laissée?»). Le troisième poème, «Diane, Séléné ...», évoque la paix «sidérale» que cherche un cœur «toujours las et toujours agité». Le cycle est maintenant encadré par le premier poème qui associe l'infini de la mer et la folie des rêves et le dernier qui s'arrête sur le déchirement d'un être "dont les désirs sont sur la terre» mais qui n’en ressent pas moins l'appel « de grands départs inassouvis».

Peut-on induire de ces modifications le sens que Fauré voulait donner à son cycle? Nous n'avons à faire qu'à des traces d'opérations et de décisions, mais rien ne nous révèle directement ce que Fauré «voulait dire». Le sens d'un texte est toujours complexe, et l'on ne peut que présenter quelques hypothèses. Le musicien a resserré, concentré le propos du poète, s'est débarrassé d'un certain nombre de thèmes, de descriptions plus précises de lieux et d'états d'âme. Il ne reste plus guère que la mer, le ciel et un sujet qui exprime son ambivalence à l'égard de la mer et du départ. Le premier poème évoque l'appel de la mer et des rêves «fous», le deuxième présente l'image ambiguë d'un départ dont on ne sait s'il provoque joie ou regrets, le troisième développe une aspiration vers la paix nocturne tandis que le quatrième et dernier semble bien résumer la situation dans laquelle se trouve celui qui parle : il a peur des élans qui emportent d'autres êtres vers des lointains inconnus mais il ressent en même temps une irrépressible et secrète envie de partir.

Est-ce que les poèmes décrivent l'état d'âme de Jean de la Ville de Mirmont ou celui de Fauré? Il est vrai, comme l'écrit Charles Kochlin, que «Gabriel Fauré eut ce don absolu, quasiment génial, de s'identifier aux poètes» (Kœchlin 1927 , p. 46). Et Charles Panzéra a souligné l'extraordinaire «communion» qui a rassemblé le poète de vingt-huit ans et le musicien qui en avait alors soixante et douze (Panzéra 1964, p. 117). Mais il faut se garder des dérives de l'interprétation. Tout ce que l'on peut dire, c'est que Fauré a sans doute senti en lui un écho aux inquiétudes du poète : inquiétudes du vieillard qui songe à la mort mais aussi une conception de la musique qui en faisait l'équivalent des «grands 
départs» rêvés par le poète. Voici ce que le musicien écrivait à sa femme à propos de l'andante de son Second Quatuor, dans lequel on entend un sourd motif de cloches :

Sur ce bourdonnement s'élève une vague rêverie qui, comme toutes les vagues rêveries, serait littérairement intraduisible. Seulement, n'est-il pas fréquent qu'un fait extérieur nous engourdisse ainsi dans un genre de pensées si imprécises qu'en réalité elles ne sont pas des pensées, et qu'elles sont cependant quelque chose où on se complait? Désir de choses inexistantes, peut-être; et c'est bien là le domaine de la musique (Lettre à sa femme du 11 septembre 1906, citée dans Nectoux 2008, p. 148).

\section{LE CYCLE DE MÉLODIES}

Voilà donc les poèmes choisis par Fauré. Quelle est alors l'organisation du cycle de mélodies qu'il en tire? Je voudrais en retenir quelques aspects en me fondant sur ce que j'appelle la mise en série, c'est-à-dire en replaçant chaque caractéristique dans l'ensemble des œuvres du musicien afin de voir dans quelle mesure elle marque continuité ou rupture dans son évolution. Il s'agit donc d'un cycle en quatre parties et, si les cycles de Fauré ne témoignent d'aucune claire régularité numérique, il est permis de rapprocher cette dernière œuvre du cycle précédent, Mirages, lui aussi composé de quatre mélodies. Il y a plus de régularité dans le nombre de strophes de chaque poème, car, dès le Deuxième Recueil de mélodies, «le plan de trois strophes tend à s'imposer» (Beltrando-Patier 1981, p. 211). Seule la deuxième mélodie, Diane, Séléné ... , n’en comprend que deux. En ce qui concerne la cohérence musicale du recueil, il n'y a pas de thèmes unificateurs qui traversent tout le cycle comme dans La Bonne Chanson.

Quelle est maintenant l'organisation tonale du cycle? Les tonalités sont les suivantes : ré, ré bémol, mi bémol, ré. Les tonalités les plus fréquentes dans les mélodies de Fauré sont, en ordre décroissant d'importance : $f a$ majeur, ré bémol majeur, mi bémol majeur, sol bémol majeur, Si bémol majeur (Beltrando-Patier 1981, p. 477-480) et nous retrouvons ici deux de ses tonalités préférées. Mais il n'y a rien qui ressemble à la structure tonale des cycles de lieder romantiques (Beltrando-Patier 1981, p. 194-196) comme les enchaînements par quintes de Dichterliebe. Si dans La Bonne Chanson les mélodies s'enchaînent par degrés conjoints descendants dans la première partie (mélodies 1 à 6) et présentent dans la deuxième partie (7 à 9) une structure «embrassée» qui peut déjà faire penser à L'Horizon chimérique (si bémol majeur, sol majeur, si bémol majeur), il n’y a d'organisation systématique des tonalités dans aucun des autres recueils.

Peut-on accorder une signification précise au choix des tonalités ré, ré bémol, $m i$ bémol, ré ? Voici comment Madame Beltrando-Patier, dans son ouvrage déjà cité, décrit la signification des tons bémolisés : «Par la suite, Fauré choisit de préférence les tons majeurs bémolisés, tons romantiques et pianistiques par excellence, où la position allongée sur le clavier donne un toucher velouté et non percutant. [...] Les tons bémolisés ont, en outre, l'avantage de moduler aisément vers la lumière (vers les tons comportant moins de bémols) ... [...] Le ton majeur à armature bémolisée est donc mystérieux au départ et tend à 
s'éclaircir. Il peint à merveille les nuances de la nuit, du secret, du sentiment et du rêve. Mais, cette distinction faite, il est difficile d'aller plus loin et d'attribuer à chaque ton en particulier une signification précise» (Beltrando-Patier 1981, p. 479-480). Dans un ouvrage peu connu, publié à Lausanne en 1921 et intitulé La Musique et la vie intérieure, Lucien Bourguès et Alexandre Denéréaz ont suggéré qu'une bonne part de l'éthos des tonalités vient, si l'on exclut les cas d'oreille absolue, d'une part de la région sonore concernée - «la couleur affective variera infiniment plus de région aiguë à région grave, le ton restant le même, que de ton à ton voisin, la région restant approximativement la même» (Bourguès et Denéréaz 1921, p. 307) - et d'autre part de leur rapport à la gamme de $d o$ «servant d'étalon affectif parce que la plus habituelle»: «Plus le ton est bémolisé, moins il est excitant, association due également à la comparaison cénékinesthésique avec le ton de do" (Bourguès et Denéréaz 1921, p. 308). Je me garderai bien d'entrer dans une discussion générale du sens des tonalités qui n'a pour l'instant pas de solution très claire - surtout si l'on tient compte des fréquentes transpositions pour voix différentes - et préfère en rester à une observation qui porte seulement sur leur succession dans L'Horizon chimérique. Ce que l'on entend dans le cycle, c'est le déplacement d'un demi-ton de ré à ré bémol puis le déplacement d'un ton de ré bémol à mi bémol et enfin le retour, à distance d'un demi-ton, à la tonalité première de ré.

Ce qui nous conduit à une dernière caractéristique du recueil, sa structure cyclique : la dernière mélodie nous ramène à la tonalité de ré de la première et, d'une certaine façon, on n'a fait que tourner autour. Mais il ne s'agit pas seulement de l'encadrement du cycle par la même tonalité, il y a en effet un certain nombre de correspondances entre le début et la fin du cycle : selon la formule un peu énigmatique de Charles Panzéra, le dédicataire de l'œuvre, la dernière phrase du dernier poème «synthétisant tout le cycle, ramène l'œuvre à son point de départ» (Panzéra 1964, p. 125). C'est d'abord vrai pour le texte : le dernier vers du cycle, "Car j'ai de grands départs inassouvis en moi», semble bien revenir aux horizons ouverts par le premier : «La mer est infinie et mes rêves sont fous». Mais c'est vrai aussi pour la musique, comme le montre Carlo Caballero dans le livre qu'il a consacré à l'esthétique de Fauré (Caballero 2001, p. 101-103). Dans la première mélodie, «La mer est infinie», la ligne vocale monte, dans la première phrase, de ré à la dominante la à laquelle elle reste ensuite attachée jusqu'à la fin. À cette montée de la tonique à la dominante répond le mouvement inverse de la dernière mélodie "Vaisseaux», elle aussi en ré majeur, dont la ligne vocale part de la dominante la qu'elle prolonge jusqu'à la descente attendue de la dernière phrase jusqu'au ré, retour à la tonique encore souligné par l'octave descendante de l'antépénultième mesure (mesure 26).

\section{De la PoÉSIE À la MUSIQUe : LA POÉSIE RÉCITÉE}

Telle est la physionomie globale du cycle, l'aboutissement du travail du musicien, mais ce que je voudrais continuer à suivre, c'est le long chemin qui mène de la page du poète lue par le musicien jusqu'à la partition de la mélodie qu'il finit par composer. Je me suis arrêté aux choix et aux modifications qui l'ont 
conduit aux quatre poèmes retenus. Et maintenant, que va-t-il faire? Comment procède-t-il? Il faut d'abord rappeler que, un peu comme Mallarmé, Fauré ne voulait pas laisser après lui de traces des étapes de son travail de composition (Caballero 2001, p. 238-251). C'est ainsi qu'il écrivait dans sa dernière lettre à sa femme un mois avant sa mort:

À Paris, je me mettrai un peu chaque jour à te donner, pour les livrer aux flammes, toutes mes esquisses, tous mes brouillons, tout ce dont je veux que rien ne subsiste après moi. C'est un grand souci que j'éprouvais quand j'étais malade. Tu m’aideras à le satisfaire. (cité dans Nectoux 2008, p. 615)

Ce souhait a été exaucé puisqu'on ne conserve que peu de chose des esquisses et du travail préparatoire du compositeur (Nectoux 2008, p. 456).

Cependant, grâce à quelques confidences, on sait quelque chose qui nous intéresse directement. Voici ce que note en 1902 dans son journal une de ses interprètes amateurs, Emilie Girette :

Il me disait qu'il composait dans sa tête d'abord, par les paroles; c'est la poésie qui l'inspire - la mélodie se forme peu à peu en lui, même sans y penser cela mûrit inconsciemment et ensuite vient le travail de mise au point qui n'est pas le plus facile, au contraire (cité dans Nectoux 2008, p. 455-456).

Fauré prenait donc le vers au sérieux. Il ne faut pas oublier qu'à cette époque, la poésie n'était pas réduite à la portion congrue qu'on lui réserve aujourd'hui et jouait un rôle social qui était en partie au moins fondé sur le nouveau statut que la poésie avait acquis avec le Romantisme:

La poésie (le vers) est au XIX ${ }^{\mathrm{e}}$ siècle l'une des formes les plus répandues de la communication. Revues, journaux, livres, mais aussi correspondances, manuels scolaires ... véhiculent poèmes et poésies d'auteurs connus et inconnus. Lectures publiques et privées, récitations de tout ordre ont lieu en bien des occasions, dans une fraction importante de la société. (Pich 1977, p. 10)

Le plus souvent, le poète savait que sa poésie serait récitée en public, par lui ou par un acteur. On peut dire qu'il y avait bien à cette époque, pour reprendre les mots de Georges Mounin, «communication poétique» (Mounin 1969), parce que, au moins pour la poésie «traditionnelle», c'est-à-dire en laissant de côté ce qui commençait à être de la poésie d'avant-garde, la langue poétique était comprise par tout le monde. Ce n'est évidemment plus le cas aujourd'hui : la poésie "compréhensible» s'est maintenant réfugiée dans la chanson. Il y a quelqu'un qui a récemment mis en musique et chanté le deuxième poème du cycle de Fauré (en conservant la dernière strophe, supprimée par Fauré) : ce n'est pas Pierre Boulez, c'est Julien Clerc.

Précisément parce qu'elle était faite pour être récitée, elle n'était pas lue ou «parlée» comme de la prose. Écoutons le témoignage d'un expert, Valéry:

Un poème, comme un morceau de musique, n'offre en soi qu'un texte, qui n'est rigoureusement qu'une sorte de recette; le cuisinier qui l'exécute a 
un rôle essentiel. [...] Qu'il ne faut point, dans l'étude d'une pièce de poésie que l'on veut faire entendre, prendre pour origine ou point de départ de sa recherche, le discours ordinaire et la parole courante pour s'élever de cette prose plane jusqu'au ton poétique voulu; mais au contraire, je pensais qu'il faudrait se fonder sur le chant, se mettre dans l'état du chanteur, accommoder sa voix à la plénitude du son musical, et de là redescendre jusqu'à l'état un peu moins vibrant qui convient aux vers. [...] L'intention de raccorder la poésie au chant me semble exacte dans son principe et conforme aux origines comme à l'essence de notre art. C'est dans cet esprit que j'ai fait - il y a deux ans - l'expérience d'appeler une cantatrice à étudier avec moi et à dire devant le public des poèmes de Ronsard. Je ne sais si l'événement m’a justifié; du moins il a tourné à la gloire de Mme Croiza, qui a osé. (Valéry [1926] dans 1960, p. 1255-1256)

Il vaut la peine d'ajouter que Claire Croiza a été une grande interprète de la mélodie française et de Fauré, qui lui a dédié une des mélodies du Jardin clos. La récitation de la poésie autour de 1900 est bien une espèce de chant, comme en témoignent les quelques enregistrements que l'on conserve des grandes comédiennes et comédiens de l'époque. Il existe plusieurs styles de diction : la «mélopée uniforme» (Proust 1987, p. 441) de la Berma-Sarah Bernhardt s'oppose à la diction violemment expressive de Julia Bartet, que connaissait bien Fauré, mais l'essentiel réside dans la distance que la récitation des vers doit marquer par rapport à la lecture de la prose ou à la conversation courante.

Les rapports entre poésie et musique ont considérablement varié selon les époques et selon les genres et Rossana Dalmonte a présenté, dans le tome 2 de l'encyclopédie Musiques, une typologie des rapports possibles entre les deux (Dalmonte 2004). Elle distingue quatre modalités principales dans leurs relations : l'assimilation de l'une par l'autre; l'altérité et l'opposition lorsque la musique est indifférente ou s'oppose au contenu sémantique des paroles; la coopération enfin lorsque, sous des formes évidemment diverses, il existe entre les deux des rapports de correspondance ou de complémentarité. Je préfèrerais pour ma part me placer, non sur le terrain des possibles relations sémantiques entre les deux formes symboliques, mais sur le terrain du statut et de la dignité que l'on accorde à chacun des deux partenaires. On peut dire alors qu'au XIX ${ }^{\mathrm{e}}$ siècle et si l'on se restreint au domaine de la mélodie et du lied, les rapports entre poésie et musique sont des rapports de respect mutuel et donc d'authentique coopération. C'est sans doute un des moments, en cela comparable à la seconda prattica de Monteverdi, où le musicien prend le plus au sérieux le texte poétique. Voici comment Johann Friedrich Reichardt (1752-1814), l'un des créateurs du lied moderne, définissait les relations du texte et de la musique :

Les mélodies naissent d'elles-mêmes, toujours d'une lecture répétée de la poésie, sans que j'aie besoin de les chercher, et tout ce que j'y ajoute, c'est que je les répète longtemps, avec de petites différences. Je ne les écris que lorsque je sens que l'accent grammatical, l'accent logique, l'accent pathétique et l'accent musical sont bien liés les uns aux autres; ainsi, la mélodie à la fois déclame juste et chante agréablement (cité par Gilles Cantagrel dans François-Sappey et Cantagrel 1994, p. 541). 
En France, c'est Gounod qui, sans doute sous l'influence du lied, est l'un des premiers à se préoccuper à nouveau de prosodie : «Ce n'est point un de ses moindres mérites de nous avoir ramené vers la grande tradition du passé, en basant sa musique vocale sur la justesse de la déclamation» (Saint-Saëns 1885, p. 262, cité dans Noske 1954, p. 148).

Je verrais volontiers un signe de cette fidélité au texte à la fin du XIX ${ }^{\mathrm{e}}$ siècle dans les habitudes de Hugo Wolf (1860-1903):

Accompagnant souvent au cours de ses tournées le ténor Ferdinand Jäger, créateur du rôle de Parsifal, Wolf avait instauré un rite immuable qui, après avoir dérouté le public, finit par lui valoir de grands succès : il déclamait lui-même le poème depuis son piano avant de laisser s'exprimer le chanteur. Le compositeur a bel et bien intitulé tous ses lieder «Gedichte von ..., vertont von Hugo Wolf», littéralement «Poèmes de ..., mis en musique par Hugo Wolf.»

Poèmes : choisi par un musicien, ce mot a valeur de manifeste. Lu et relu, su par cœur avant d'être posé sur l'établi du compositeur, qui écrivait alors très vite (un lied par jour, et parfois plus), le poème est pour ce fin lettré un joyau qu'il a mission de présenter au monde dans un écrin de sa fabrication» (Stéphane Goldet, dans François-Sappey et Cantagrel 1994, p. 831).

\section{MUSIQUE ET VERSIFICATION ${ }^{5}$}

$\mathrm{Si}$, à la différence de Hugo Wolf, Fauré ne déclame pas en public les poèmes qu'il met en musique, il n'en reste pas moins que, selon le témoignage déjà cité d'Émilie Girette, il se livre bien à une espèce de récitation intérieure, puisqu'il compose «dans sa tête d'abord, par les paroles». Quels problèmes a-t-il à résoudre tout en se laissant aller à son "inspiration »? Il nous faut entrer à nouveau dans l'atelier du musicien : selon la formule attribuée à l'historien d'art Aby Warburg, le diable est dans les détails, ou plutôt - je préfère la formule positive, attribuée cette fois à Flaubert - le bon Dieu est dans le détail. Car, comme on ne manquera pas de le constater dans ce qui suit, la plupart des discussions qui portent sur la mélodie et le lied n'accordent pas une assez grande attention aux caractéristiques propres du poème et de son langage. Je précise que je laisse de côté les discussions portant sur la compatibilité théorique entre musique et langage ou musique et poésie (Ruwet 1972), car la musique vocale est un fait majeur et longtemps dominant de la production musicale et il me semble plus intéressant de me placer sur le terrain concret de leurs relations complexes et variables, et d'abord sur celui de la métrique et de la prosodie.

Le musicien a affaire à deux formes symboliques distinctes, la poésie et la musique. Mais, pour bien comprendre son travail, il est utile de revenir un peu en arrière et de s'intéresser un instant au travail du poète. Celui-ci travaille

5 Tandis que la versification est l'étude de tous les niveaux de structuration des vers, la métrique est l'étude des principes et des régularités qui en caractérisent l'organisation interne. La prosodie est, au sens linguistique du terme, l'étude des caractéristiques phoniques des unités non segmentales (durée, hauteur, accent, intonation ...) qui peuvent ou non intervenir dans la métrique (Molino et Gardes-Tamine 1992, p. 26) 
déjà sur deux plans. Il y a d'un côté une langue avec laquelle il parle et écrit en prose, puisque, comme le fait remarquer le Maître de Philosophie au Bourgeois gentilhomme, «tout ce qui n'est point vers est prose». Il y a de l'autre côté un système de versification qui vient se superposer au système linguistique : «La poésie est l'application d'une organisation métrico-rythmique sur l'organisation linguistique» (Molino et Gardes-Tamine 1992, p. 8). Le poète construit son œuvre en tenant compte à la fois des possibilités de la langue et des contraintes imposées par la versification : il parle et écrit en vers. Le poète doit donc «faire entrer » ce qu'il a à dire dans le cadre défini par les conventions poétiques régnantes.

La situation du musicien n'est au fond pas tellement différente : il doit faire entrer ce qui est maintenant un poème dans une nouvelle organisation. La poésie chantée implique en effet trois niveaux d'organisation (Molino 2002) : un niveau linguistique, qui correspond aux caractéristiques phoniques, prosodiques et morphosyntaxiques de la séquence parlée; un niveau métrique, dans lequel apparaissent les unités et contraintes du système de versification (nombre de syllabes, accent, hémistiche, vers, strophe); un niveau musical avec ses unités et contraintes propres. Lorsqu'un musicien compose une mélodie, il doit associer une organisation linguistique et métrique qui lui est donnée par le poème qu'il veut "mettre en musique» et une organisation musicale avec laquelle la précédente va plus ou moins exactement s'accorder.

Regardons maintenant de plus près les unités et niveaux de ces deux organisations afin de voir de quelle façon ils peuvent être mis en correspondance, comme cela apparaît dans le schéma simplifié suivant :

$$
\begin{array}{ccc}
\begin{array}{c}
\text { syllabe } \\
\text { note }
\end{array} & \text { vers } & \text { strophe } \\
\text { wphrase» } & \text { forme strophique }
\end{array}
$$

Quelles sont donc les relations possibles entre les deux niveaux? En ce qui concerne les relations entre syllabe et note, le chant mélismatique s'oppose au chant syllabique, chacun correspondant à des genres, à des époques et à des places particulières dans le texte : il y a davantage de mélismes dans l'opéra que dans la chanson populaire. Selon les habitudes de la mélodie du XIX ${ }^{\mathrm{e}}$ siècle, Fauré utilise des mélismes, mais, sauf dans les mélodies de caractère «italien» («Sérénade Toscane», "Après un rêve»), il en use avec discrétion. Dans "Lydia», on en trouve à la mesure 9 (figuralisme pour traduire «fluide») et à la mesure 16 (correspondant à "baisers de colombe», situé à la fin de l'unité musicale et marquant un sommet expressif). Ils reviennent dans la deuxième strophe musicale aux mesures 27 et $34^{6}$, mais, comme on s'approche de la fin, Fauré ajoute de nouveaux mélismes aux mesures 31 («baisers») et 35 ("puisse mourir»). Au cours de sa carrière, Fauré passe progressivement au chant syllabique, auquel il se tient dans ce qu'on appelle souvent sa troisième période, c'est-à-dire après 1906 (Orledge 1983, p. 142 et 255) : c'est le cas de L'Horizon chimérique, qui est strictement syllabique.

6 On peut noter que, dans la mesure 27, pour rester fidèle aux suggestions du texte, Fauré déplace le mélisme afin de le faire porter sur la syllabe «jeune». 
La strophe est, d'un point de vue anthropologique, étroitement liée à la musique et à la danse (Molino et Gardes-Tamine 1988, p. 14-19). En particulier, la structure strophique est une caractéristique dominante de la chanson folklorique européenne, que l'on retrouve aux origines de la chanson, de la romance, du lied et de la mélodie (Nettl 1973, p. 39-42). C'est dans le cadre de l'évolution du lied, lorsqu'il passe du «Volkslied» au «Kunstlied», que l'on voit apparaittre une grande diversité de solutions pour mettre en correspondance structure poétique et organisation musicale (Gut 1994, p. 69-79). Le compositeur dispose ainsi de toute une palette de possibilités, depuis la forme strophique simple, dans laquelle la même musique est reprise pour chaque strophe, jusqu'à la forme «durchkomponiert», qui ne comporte pas de répétitions ou reprises systématiques de séquences mélodiques, en passant par la forme strophique variée et les formes «tripartites» - forme "Bar» $\mathrm{AAB}$ et forme $\mathrm{ABA}$, souvent dite forme lied. On retrouve dans l'histoire de la mélodie française une évolution comparable à celle qui avait fait passer du «Volkslied» strophique au «Kunstlied» «durchkomponiert». C'est ainsi que Fauré passe d'une forme strophique plus ou moins régulière dans son premier recueil à la forme tripartite (ABA, $\mathrm{ABA}^{\prime}$ ) dans le second et enfin à une forme continue $(\mathrm{ABC})$ dans le troisième et dans les cycles suivants (Beltrando-Patier 1981, p. 187-279). Mais il est important de souligner que, même dans le cas d'une mélodie "durchkomponiert», la strophe joue toujours un rôle essentiel dans l'organisation du discours musical.

Entre la syllabe et la strophe se situe l'unité métrique fondamentale, le vers. Il y a traditionnellement une relation étroite entre d'une part les vers ou groupes de vers et d'autre part l'organisation musicale : selon leur longueur, un ou deux vers correspondent à des ensembles de quatre ou groupes de quatre mesures (carrure). C'est le cas aussi bien dans les lieder de Schubert que dans les mélodies du XIX ${ }^{\mathrm{e}}$ siècle français jusqu'à l'époque de Fauré et Debussy, mais ici aussi l'évolution va dans le sens de la disparition de la carrure. Dans «Lydia», comme on l'a vu, Fauré soumet la musique à la forme strophique et les vers à la carrure, mais il abandonne progressivement ces deux contraintes, dont il n'y a plus trace dans L'Horizon chimérique. Il n'a donc plus de difficultés pour intégrer dans les mélodies les enjambements, comme le prouvent, dans «La mer est infinie ...», les enjambements des vers 3-4 (mesures 5-7) et 9-10 (mesures 21-25).

\section{Questions de métriQue et de PRosodie}

Mais le vers est le lieu d'une grande "question disputée " : quelle est la nature du vers français? Est-il purement syllabique ou accentuel? Rappelons les données de base du débat. Selon la conception traditionnelle (Lote 1949-1996; Elwert 1965; Deloffre 1973; Molino-Tamine 1992, p. 23-26), le vers français est défini par trois caractéristiques : le nombre de syllabes, la rime et, pour les vers «longs» (décasyllabe, alexandrin), une césure. Ainsi un alexandrin doit comprendre douze syllabes sans tenir compte de la présence possible d'une treizième syllabe contenant un «e muet» en fin de vers; la sixième syllabe, en fin d'hémistiche, et la douzième, en fin de vers, correspondent à des places 
«marquées» qui sont soumises à des contraintes d'ordre linguistique : elles doivent correspondre à des fins de mots et de groupes syntaxiques. Le vers suivant du poète contemporain Denis Roche a bien douze syllabes, mais ce n'est pas un alexandrin classique puisque la sixième et la douzième syllabes sont situées au milieu d'un mot :

La plaine où est sensi/ble le moindre dessè/Chement $[\ldots]$

Selon cette conception, la versification française repose donc sur une métrique purement syllabique. Il semble bien que pendant longtemps la diction n'ait souligné que la dernière syllabe «masculine» du vers (c'est-à-dire non constituée d'un «e» muet) et de l'hémistiche, ce qui conduisait, dans le cas des vers longs, à une réalisation épousant un «schéma circonflexe» : la voix montait jusqu'à la fin de l'hémistiche et redescendait jusqu'à la fin du vers (Lote, 19491996). Lorsque la diction ou la mise en musique respectent systématiquement et exclusivement les accents qui portent sur la dernière syllabe masculine du vers et éventuellement la dernière de l'hémistiche, il est commode de parler de lecture métrique, en donnant à l'expression un sens plus restreint que celui que lui donnait Jean-Pierre Ouvrard (Ouvrard 1981) : cette lecture métrique ne fait aucune part aux caractéristiques prosodiques (accent, longueur) de la séquence linguistique qui constitue le vers.

Cependant, comme le souligne le spécialiste russe de versification européenne M. L. Gasparov, la versification des langues romanes et en particulier la versification française ont longtemps souffert d'un complexe d'infériorité à l'égard de la versification quantitative des langues anciennes et de la versification accentuelle des langues germaniques :

European syllabic verse always had a kind of inferiority complex, because it failed to develop an additional means of organizing material similar to that of classical verse; in fact, a division into feet (Gasparov 1996, p. 143).

Ainsi s'explique qu'à partir du XVI ${ }^{\mathrm{e}}$ siècle, la théorie du vers français se soit préoccupée de l'application au français des principes de la versification latine et grecque fondée sur la longueur des syllabes (opposition des syllabes brèves et longues), tandis que des poètes tentaient d'écrire des vers «mesurés à l'antique». Une des conséquences les plus fécondes de ces tentatives a été d'orienter les musiciens vers la prise en compte et le respect de la prosodie. C'est ainsi qu'Isabelle His a pu parler de l'«Évolution du souci prosodique dans la mise en musique du français de la seconde moitié du XVIe siècle : le cas de Claude Le Jeune» (His 1998) et qu'Olivier Bettens a pu écrire la "Chronique d'un éveil prosodique (1547-1643)» (Bettens 2008).

C'est qu'en dehors des unités métriques et de leurs frontières, les séquences linguistiques qui «remplissent» le vers ont une organisation prosodique propre reposant sur la durée et sur l'accent. La durée n'a en français qu'un rôle phonologique très limité. Le rendement de l'opposition entre voyelle brève et voyelle longue est très faible, puisqu'elle ne sert à différencier qu'un petit nombre de mots tels que : maître / mettre ou pâte / patte (dans ce cas l'opposition de 
durée s'accompagne d'une différence de timbre entre les deux «a») et ces quelques oppositions tendent à disparaître. Quant à l'accent, sa nature et son statut en français ne sont aujourd'hui encore pas bien compris (Lacheret-Dujour et Beaugendre 1999). Le consensus actuel le définit comme accent final de groupe (Carton 1979)7. Il se place sur la dernière syllabe masculine du mot isolé ou du syntagme dans lequel le mot est inséré et se caractérise avant tout par la durée et secondairement par l'intensité et la hauteur. Ainsi se constituent des groupes rythmiques d'étendue variable, les groupes les plus fréquents ayant 3 ou 4 syllabes. Mais, comme la délimitation des groupes est liée à la syntaxe et à la sémantique, on comprend que leur découpage dépende en partie au moins des choix du locuteur. Voici par exemple une phrase de Gide telle qu'il la dispose dans Les Nourritures terrestres en allant à la ligne après la préposition "pour» et dans laquelle j’ai indiqué par des barres inclinées quelques-uns des groupes rythmiques que le locuteur peut distinguer :

... Mais je me sens/ à présent,/ Nathanaël,/ plein de pitié/ pour/ les fau/tes délica/tes des ho/mmes.

L'accent ne peut en principe porter que sur les syllabes dites accentogènes ou accentuables, qui correspondent aux dernières syllabes masculines des mots lexicaux (noms, adjectifs, verbes et adverbes polysyllabiques), tandis que les mots grammaticaux (déterminants, pronoms, prépositions, conjonctions et adverbes monosyllabiques) sont des proclitiques, c'est-à-dire des mots dépourvus d'accent propre qui forment avec le mot qui suit une unité accentuelle. On peut donc parler, en parallèle à la lecture métrique définie tout à l'heure, d'une lecture prosodique (proposée par His 1998, p. 87 et Bettens 2008) lorsque la diction ou la musique soulignent d'une façon ou d'une autre les syllabes longues et/ou accentuées.

Organisation et lecture métrique d'un côté, organisation et lecture prosodique de l'autre, telles sont donc les données à partir desquelles se pose la question de la nature du vers français, que l'on peut résumer de la façon suivante : étant donné le fondement syllabique traditionnel de la versification française, quel rôle jouent dans le vers la durée et l'accent? Ils peuvent d'une part jouer un rôle constructif explicite. C'est ce qui s'est produit au moins deux fois dans l'histoire du vers français : au XVI ${ }^{\mathrm{e}}$ siècle, au moment où l'on tente d'écrire des vers mesurés à l'antique et à la fin du XIX ${ }^{\mathrm{e}}$ siècle, lorsque poètes et théoriciens veulent substituer une versification accentuelle à la versification syllabique traditionnelle. Mais ils peuvent aussi jouer un rôle sous la forme non de principes ou de règles explicitement posées, mais sous la forme de régularités observées. C'est le cas par exemple pour l'apparition progressive d'une organisation de l'alexandrin fondée sur la mise en relief des positions 4 et 8 parallèlement à l'affaiblissement des contraintes portant sur la dernière syllabe de l'hémistiche, développement qui conduit à l'apparition du trimètre romantique. Ils peuvent enfin jouer un rôle dans la diction et c'est ici qu'apparait l'intérêt exceptionnel

7 Je laisse de côté les autres types d'accent comme les accents dits secondaires (contretoniques) ou les accents d'insistance, qu'il serait nécessaire de prendre en compte pour une analyse plus complète. 
du témoignage apporté par la mise en musique de la poésie, qui donne une idée de la façon dont les gens d'une époque donnée percevaient, lisaient et/ou entendaient les vers (Lote, 1949-1996, passim).

On comprend alors pourquoi il est nécessaire d'adopter une perspective historique. Il n'y a pas d'essence de la versification française : les conceptions, la pratique et la diction des vers ont changé au cours du temps. Comme l'a fait remarquer M. L. Gasparov, le développement et l'évolution d'un système de versification s'opèrent dans le cadre d'un réseau d'interactions : entre les caractéristiques de la langue et les influences culturelles internationales, entre les exigences de la langue et les exigences du système de versification adopté (Gasparov 1996, p. 293-295). C'est un de ces phénomènes d'interaction qui s'est produit au $\mathrm{XVI}^{\mathrm{e}}$ siècle lorsqu'on a voulu transposer au français la métrique quantitative du latin et du grec. Comme on l'a vu, il n'y a pas d'opposition phonologique en français entre syllabes brèves et longues, ce qui rendait à peu près impossible une transposition stricte d'un système à l'autre. Il existe cependant des relations étroites entre organisation métrique et organisation prosodique. D’une part en effet, les syllabes métriques (fin de vers et hémistiche) sont des syllabes accentuées puisqu'elles correspondent normalement à des fins de groupes accentuels. Il existe d'autre part une forte corrélation entre allongement des voyelles et accent : les voyelles accentuées sont en général plus longues que les voyelles inaccentuées (Léon 1966, p. 18-20). On comprend alors comment les tentatives de versification quantitative ont pu conduire à prendre en compte, d'une manière approximative et non théorisée, l'organisation accentuelle du vers. Ce dont témoigne la musique, c'est l'évolution, bien mise en valeur par George Lote, qui se fait dans le sens d'une «naturalisation» de la diction poétique et, parallèlement, de la mise en musique. Ce qui veut dire simplement que l'on passe d'une diction qui souligne exclusivement les fins de vers et d'hémistiche à une diction qui tient compte de la place des accents au sein du vers. L'évolution conduit ainsi, à travers l'air de cour, au récitatif de Lulli, qui est, pour reprendre la formule de Georges Lote, «le premier musicien français qui indique sans défaillance sur quelles syllabes tombent les toniques de notre langue» (Lote 1949-1996, tome VI, p. 351). C'est un constat que vient de confirmer la récente étude de Jean-Noël Laurenti (Laurenti 2008).

Cette transformation parallèle de la diction et de la musique se réalise dans une grande confusion théorique, puisque grammairiens et poètes n'avaient pas en général conscience de l'existence d'un accent «tonique» en français, dont la notion n'émerge qu'au début du XIX siècle (Chaurand 1991). A la fin du XVIII siècle encore, Marmontel affirmait qu'il n'y avait pas d'accent "prosodique», c'est-à-dire tonique, en français et qu'il y avait seulement un accent «oratoire» que l'on pouvait placer sur à peu près n'importe quelle syllabe. Il donnait comme exemple un vers de Phèdre:

Malheureuse ! quel mot est sorti de ta bouche!

qui, selon lui, pouvait recevoir des accents aussi bien sur la première que sur l'avant-dernière syllabe de «malheureuse», aussi bien sur "quel» que sur «mot » ... (Marmontel, «Accent», dans [1787] 1879, tome I, p. 67). Mais en même 
temps Marmontel est bien conscient de l'existence d'un accent de mot : «le caractère de notre langue est d'appuyer sur la pénultième ou sur la dernière syllabe des mots» (Marmontel, «Vers», dans [1787] 1879, tome III, p. 466). Et par ailleurs il reconnaît que le vers peut avoir des coupes à l'intérieur du vers ou de l'hémistiche : "C'est même un art que de ménager de temps en temps dans la coupe du vers des repos plus marqués que le repos de l'hémistiche» (Marmontel, «Vers», dans [1787] 1879, tome III, p. 460). On voit donc, sur l'exemple tout à fait représentatif de Marmontel, que l'absence d'une conscience théorique de l'accent n'impliquait évidemment pas l'absence d'accentuation finale des mots et groupes de mots dans la prononciation courante ainsi que l'évolution vers un respect croissant de la prosodie dans la diction et en musique.

Le mouvement qui avait conduit au récitatif de Lulli se poursuit au XVIII siècle, comme en témoignent les déclarations de Grétry :

Je voudrais parler un instant de la règle la plus importante pour le compositeur de musique vocale, je veux dire la nécessité non seulement de déclamer les vers avant de les mettre en musique, pour qu'il soit conduit au véritable chant que doit recevoir la parole; mais surtout pour qu'il remarque les syllabes essentielles qui doivent être appuyées par le chant, qui alors s'identifie avec la parole. Pour parler distinctement en prose ou en vers, on appuie naturellement sur les syllabes les plus nécessaires, en affaiblissant l'inflexion sur celles qui le sont moins. La musique étant un second langage que l'on joint au premier, le compositeur doit donc donner la bonne note de la phrase musicale à la note qui doit être appuyée; sans cette attention, il résulte un contre sens affreux entre ces deux langages. Exemple :

Rien ne plaît tant aux yeux des belles.

En récitant ce vers, l'on doit sentir que la bonne note doit porter sur tant.

Que le courage des guerriers.

La bonne note doit être sur $r a$.

Qu'ils soient vaillants !

La bonne note sur lants. (Grétry, Mémoires ou essais sur la musique [1796], cité dans Lote 1949-1996, tome VIII, p. 96-97).

Et Georges Lote montre fort bien que les récitatifs de Gluck témoignent d'une prosodie «impeccable» : le compositeur souligne les syllabes accentuées en les plaçant sur les temps forts de la mesure et en leur donnant une longueur supérieure à celle des syllabes qui les entourent.

Du point de vue théorique, ce n'est qu'au début du XIX ${ }^{\mathrm{e}}$ siècle qu'émerge la notion d'accent «tonique» français et qu'un Italien, l'abbé Scoppa, propose une analyse accentuelle du vers (Scoppa 1811). Rapprochant le vers français du vers italien, il le considère comme composé de «pieds» correspondant aux mots et chacun constitué d'une combinaison spécifique de syllabes accentuées et de syllabes inaccentuées : «sera» est un iambe $(-/)$ et "décida» un anapeste 
$(--/)$. Les conceptions de l'abbé Scoppa provoquent de nombreuses discussions (Thieme 1916), mais il faut éviter de ne décrire l'évolution de la diction du vers et de sa mise en musique qu'à travers les analyses des théoriciens : comme nous l'avons vu, les accents intérieurs au vers et à l'hémistiche étaient déjà reconnus et pris en compte dans la musique. La théorie de Scoppa vient donc donner un fondement à une pratique largement antérieure, conduisant à la conception qui se trouve présentée dans les ouvrages de Quicherat (Quicherat 1838 et 1850) et qui restera dominante jusqu'au $\mathrm{XX}^{\mathrm{e}}$ siècle : l'alexandrin par exemple est défini comme ayant deux accents "nécessaires» à la fin de l'hémistiche et du vers et deux accents «libres» dont la place varie à l'intérieur de chaque hémistiche.

Pour les compositeurs, la situation semble avoir été assez confuse au cours du XIX ${ }^{\mathrm{e}}$ siècle comme en témoignent les ouvrages et discussions portant sur les relations entre prosodie poétique et prosodie musicale (Noske 1954, p. 3661). La conception quantitative du vers se maintient longtemps et c'est elle qui apparaît encore dans un des très rares témoignages que nous avons de la façon de procéder des compositeurs. Il est fourni par le musicien Henri Büsser, qui rapporte que son maître Gounod

avait l'habitude, quand il composait une œuvre lyrique, d'indiquer sur un exemplaire copié du livret les longues et les brèves des vers à mettre en musique, puis il ajoutait au-dessus des paroles des notes éparses ne portant aucune indication de mesure ni d'armure (dièses et bémols) (Büsser 1961, p. 89-90, cité dans Beltrando-Patier 1981, p. 328).

De nombreux observateurs soulignaient que, dans des genres comme la romance ou l'opéra, les musiciens ne tenaient guère compte du rythme propre des vers. Voici comment Saint-Saëns décrivait la situation :

C'est dans l'école du milieu de ce siècle que s'est fait jour le dédain du vers et de la prosodie. On avait imaginé qu'en dehors de la césure et de la fin du vers, aucune syllabe ne portant d'accent, l'accent musical pouvait se poser à volonté; et ce n'était pas seulement les musiciens qui pensaient ainsi, mais aussi les poètes; quand l'un d'eux mettait lui-même des paroles sur un air connu, il le faisait d'après ce principe. Le résultat était un affreux charabia auquel on s'était accoutumé, tout en remarquant qu'il était impossible, en écoutant un morceau de chant, d'entendre les paroles (Saint-Saëns 1885, p. 261-262, cité dans Noske 1954, p. 147).

Et il donne un exemple des «fautes» de prosodie que l'on trouve dans les œuvres d'Offenbach (les voyelles musicalement accentuées sont en majuscules) :

Et VOI-là comme

Un GA-lant homme

Évite tout désagrément.

(Offenbach, La Belle Hélène, cité dans Noske 1954, p. 53)

Il est clair que ces déplacements d'accent pouvaient jouer un rôle comique, mais on trouve des «fautes» du même genre dans les premières mélodies de 
Fauré, ce qui montre bien qu'il s'agissait d'un phénomène assez courant. Voici par exemple comment est mis en musique le vers 5 de «Lydia» (mesures 11-12) :

Le jour qui luit est le mei- lleur //noire/croche/croche/noire pointée/croche // noire pointée/croche/blanche

On constate que les articles, qui correspondent à des notes de durée plus importante que celles qui correspondent aux substantifs, sont situés sur le temps fort de la mesure. On ne trouve généralement plus de telles «fautes» dans les mélodies suivantes de Fauré, car une solution à peu près consensuelle s'était progressivement dégagée (Noske 1954, p. 57) : il s'agissait de placer les syllabes accentuées sur les temps forts et les syllabes non accentuées sur les temps faibles ou parties faibles du temps, solution qui, notons-le, était habituelle dans le lied et ne faisait que retrouver la tradition de l'opéra français. Mais en fait ce «purisme» qui triomphe autour de 1900 (Noske 1954, p. 55-59) est purement théorique et ne saurait décrire la diversité des solutions choisies par chaque musicien.

\section{PAysages métrico-RYThMiQues de L'Horizon CHIMÉRIQUe}

Quelles sont donc les données de la situation «métrico-rythmique» devant laquelle se trouvent aussi bien le musicien lorsqu'il veut mettre en musique un poème relevant de la versification traditionnelle que l'amateur lorsqu'il veut le lire? Il y a, du point de vue phonétique, des syllabes accentuables, qui correspondent aux dernières syllabes masculines des mots lexicaux situés en fin de groupe rythmique, et, parmi ces syllabes accentuables, les syllabes métriques qui correspondent aux fins de vers et d'hémistiche. Dans la versification «classique» (XVII ${ }^{\mathrm{e}}-\mathrm{XX}^{\mathrm{e}}$ siècle), les fins de segment métrique (vers et, pour les vers longs, hémistiches) doivent correspondre à des fins de groupe accentuel : l'accent de groupe doit coïncider avec la dernière syllabe de l'hémistiche et du vers. Mais, comme on l'a vu, il n'existe pas de règles strictes pour délimiter les groupes accentuels. Je puis par exemple, dans le vers «Le jour qui luit est le meilleur", placer des accents sur la deuxième, la quatrième et la huitième syllabe (jour, luit, -lleur), sur la quatrième et la huitième (luit, -lleur) ou sur la huitième seulement (-lleur), qui est la seule syllabe métrique. Mais je peux aussi, comme le fait Fauré dans sa mélodie, placer sur le premier temps de la mesure les deux articles «le» et les syllabes «luit» et «-lleur» sur le troisième. Il y a donc une grande marge de liberté dans la récitation ou la mise en musique d'un vers.

La structure métrico-rythmique du même vers de «Lydia» peut être schématisée de la façon suivante (j'indique par un trait une fin de groupe rythmique «normal» et par deux traits les syllabes qui sont à la fois fins de groupe rythmique et de segment métrique) :

/ I II

Le jour qui luit est le meilleur

De même, j'obtiens pour le premier vers de «La mer est infinie», première mélodie de L'Horizon chimérique : 
/ // / /

La mer est infinie et mes rêves sont fous

Pour chaque vers, le musicien a donc une idée plus ou moins claire de la présence de syllabes ainsi «marquées». Si je parle d'idée plus ou moins claire, c'est qu'il est difficile de connaitre le degré exact de conscience théorique dont disposaient alors les musiciens - comme d'ailleurs les poètes - en ce qui concerne l'organisation du vers français. Il est probable que le plus souvent le musicien procédait de façon empirique, en se fiant à sa compétence de lecteur et de diseur de poésie. Il devait bien sentir, d'une façon ou d'une autre, la mise en relief de certaines syllabes, mais avec toujours la marge de liberté que laissait le système. Si l'existence d'une syllabe accentuée s'imposait en fin de segment métrique, la présence et la répartition des accents à l'intérieur de ces segments laissaient une plus grande place à l'interprétation, comme on vient de le voir pour le vers cité de "Lydia».

Le musicien a alors le choix entre deux grandes stratégies opposées, entre lesquelles se situent toutes sortes de solutions intermédiaires : suivre au plus près l'organisation métrique et rythmique du poème en la soulignant par des moyens proprement musicaux, ou au contraire soumettre plus ou moins totalement la parole à une organisation purement musicale. Plaçons-nous dans le premier cas. Quels sont les moyens dont dispose le musicien pour souligner la structure accentuelle du poème? Il dispose évidemment de l'opposition entre temps forts et temps faibles, mais il peut aussi utiliser les autres paramètres musicaux : les durées, de la double croche à la blanche, les hauteurs et les intensités mais aussi l'harmonie. On peut remarquer que, toujours pour le même vers de «Lydia», Fauré a marqué un crescendo qui culmine sur les syllabes «est le», soulignant davantage encore le poids musical de mots qui ne sont pas normalement accentués; mais il respecte par ailleurs la structure prosodique en faisant coïncider les syllabes accentuées ( $4^{\text {ème }}$ et $8^{\text {ème }}$ ) avec le troisième temps de la mesure.

Envisageons maintenant quelques-uns des problèmes que rencontre un musicien soucieux de respecter la structure accentuelle d'un poème. S'il a choisi pour la musique une structure strophique, les difficultés viennent de ce que la structure rythmique de chaque strophe ne correspond pas nécessairement à la structure musicale adoptée pour la première strophe : rien ne garantit que la place des accents rythmiques soit la même dans toutes les strophes. C'est évidemment la même difficulté qui se présente pour la phrase carrée avec les changements d'accents des vers qui doivent y entrer. On le constate facilement dans le cas de "Lydia", où la comparaison, vers par vers et mesure par mesure, des deux «macrostrophes» musicales montre les multiples ajustements de détail auxquels a dû recourir Fauré pour respecter les changements d'accents dans des vers correspondant à la même structure musicale. C'est le cas par exemple pour les mesures 3-4 et 20-22 ou pour les mesures 8-10 et 26-28.

Un autre problème est posé par le fait que le temps fort d'une mesure correspond à son premier temps et le cas échéant au troisième. Les musiciens travaillant sur une langue qui possède des déterminants (articles, adjectifs démonstratifs et possessifs) se trouvent devant une difficulté commune. Phrase 
et vers commencent souvent par un déterminant, or les déterminants sont en principe atones et s'intègrent dans le groupe accentuel du nom (ce sont des proclitiques). Ainsi s'explique la fréquence avec laquelle les mélodies et les vers commencent par une anacrouse, en allemand comme en français. On a par exemple, dans le premier lied de "Winterreise» de Schubert, "Gute Nacht», les anacrouses "Der // Mai, Das // Mädchen, die // Mutter ...», exactement comme, dans la première mélodie de L'Horizon chimérique, on a les anacrouses «La // mer (2 fois), la // brise».

Regardons maintenant la ligne vocale de cette première mélodie de L'Horizon chimérique [Annexe 5] : on ne peut que constater la grande fidélité de Fauré au rythme de l'alexandrin. Dans le premier vers dont nous avons déjà donné le schéma métrique,

/ $\quad$ / $\quad$ / $\quad$ //

La mer est infinie et mes rêves sont fous,

les accents sont soulignés par la musique : dans la montée mélodique qui fait passer du ré au la, c'est-à-dire de la tonique à la dominante, la deuxième syllabe («mer») est située sur un temps fort, la sixième («infinie») correspond à une syncope qui la prolonge sur le temps fort de la mesure suivante et la douzième («fous») vient se placer sur un temps fort. Quant à la neuvième («rêves»), elle est mise en relief à la fois par la montée du fa dièse au sol et par une opposition de durée : c'est une croche qui se détache sur les doubles-croches qui correspondent aux syllabes inaccentuées qui l'entourent («et mes» et «-ves sont»).

Pour mettre en évidence les liens possibles entre structure métrico-rythmique du vers et structure musicale, il me semble ici intéressant de suivre une suggestion d'Etienne Souriau (Souriau 1969, p. 184-218). Les spécialistes de versification française ont l'habitude, pour analyser le rythme d'un vers, de découper des «mesures » en faisant tomber la barre de mesure après l'accent, ce qui donnerait pour le vers cité :

Et mes rê/ves légers/ ne se sen/tent plus d'ai/se

Etienne Souriau propose au contraire de suivre l'exemple de la musique et de placer cette métaphorique barre de mesure avant l'accent qui coïncide ainsi avec le temps fort de la mesure :

Et mes /rêves lé/gers ne se /sentent plus /d'aise

Si l'on organise de la même façon les vers de la première mélodie de L'Horizon chimérique en marquant les fins d'unités accentuelles par un trait et les fins d'unités métriques et accentuelles par deux traits, on obtient pour la première strophe le résultat suivant :

$\mathrm{La} / \mathrm{mer}$ est infi//nie et mes /rêves sont //fous.

La mer/chante au so//leil en bat/tant les fa//laises

Et mes /rêves lé//gers ne se /sentent plus //d'aise

De dan/ser sur la //mer comme des oiseaux //soûls. 
Sur les 8 fins de segments métriques, 6 se trouvent, dans la mélodie de Fauré, sur le temps fort de la mesure musicale. La seule exception est la fin du premier hémistiche du vers 3, dans lequel la «compression» de neuf syllabes du vers dans une seule mesure répond clairement à un figuralisme évoquant la légèreté. Par ailleurs, la fin du premier hémistiche du premier vers («infinie») n’est qu'une exception apparente puisque, comme je l'ai déjà indiqué, elle correspond à une syncope qui prolonge la syllabe sur le temps fort de la mesure suivante. Ce sont évidemment les anacrouses de syllabes non accentuées qui permettent de faire correspondre les syllabes accentuées et les temps forts. C’est le cas non seulement pour les articles mais aussi pour les groupes de syllabes inaccentuées : «Et mes» (mesure 7), «-tent plus» (mesure 8), «sur la» (mesure 9) etc. Par ailleurs, Fauré respecte systématiquement la différence entre syllabe accentuée et syllabe non accentuée en donnant à la première une durée au moins double. Les séquences de durées les plus fréquentes sont du type observé par exemple dans le vers 3

Et mes /rêves lé//gers ne se /sentent plus //d'aise

— où par ailleurs les accents de groupe « rê-ve» et « d'ai-se» correspondent aux temps forts de la mesure -, soit deux doubles-croches suivies d'une croche ou d'une note de durée supérieure. Ce rythme anapestique (non accentué-non accentué-accentué), dont il y a 32 occurrences dans les 34 mesures de cette mélodie, correspond bien au découpage rythmique le plus fréquent de l'alexandrin classique, composé de quatre groupes accentuels de trois syllabes $(3+3$ / $3+3)$, et il vaut la peine de noter que c'est un des rythmes caractéristiques du récitatif de Lully.

Fauré prend donc au sérieux les fins de segments métriques et les souligne par des moyens musicaux, mais ce respect ne signifie pas parallélisme strict, car d'une part le musicien dispose de différents paramètres pour opérer ce soulignage et c'est à lui d'autre part qu'appartient la décision de respecter ou non l'accentuation des fins de segments métriques ainsi que les fins de groupes accentuels à l'intérieur de ces segments. Même dans la première strophe, dans laquelle le poète place les fins de segments métriques sur les temps forts, il conserve toute sa liberté pour souligner ou même placer les accents de groupes à l'intérieur des hémistiches. C'est ainsi que, dans le deuxième vers, il choisit de placer sur le temps fort le mot «mer» alors que l'accent normal pourrait aussi bien porter sur la syllabe "chante», ce qui permet de souligner et d'insister sur le parallélisme des deux premiers vers qui commencent tous les deux par le mot «mer»; la syllabe «chante» est elle-même soulignée par la montée mélodique, la durée, la syncope et le retour au do dièse abandonné à la mesure précédente. Mais le paysage métrico-rythmique change dans la deuxième strophe. $\mathrm{Si}$, pour le premier vers de cette strophe (vers 5), les fins de segments métriques coïncident avec des temps forts, il n'en est plus de même pour les trois vers suivants. Dans les vers 6 et 7 , les temps forts correspondent aux accents internes des hémistiches sur les deuxièmes et neuvièmes syllabes (respectivement « se» et «jouant», puis « roule» et «feront»). Ce n'est qu'avec la troisième et dernière strophe que Fauré revient à la coïncidence parfaite entre fins de segments 
métriques et temps forts. Par son irrégularité, qu'accompagne et souligne une succession de jeux modulants à partir du vers 6 , l'organisation musicale de la deuxième strophe illustre bien le mouvement et l'agitation qu'exprime le texte. On retrouvera dans d'autres domaines ce qui constitue sans doute un des traits les plus caractéristiques de l'art de Fauré : un jeu récurrent de variations subtiles qui se détachent sur un fond de régularité. Un bon exemple est fourni par les séquences d'anapestes, dont les deux premiers termes sont des doubles-croches mais dont le dernier terme peut varier selon sa place sur un temps fort et selon sa durée, qui va de la croche à la blanche.

On le voit, même lorsque le musicien est particulièrement attentif à l'organisation métrique et prosodique du poème, il le transforme et en fait une œuvre nouvelle :

When a composer sets a pœm to music he creates an independent work of art bearing a complex, ultimately unresolvable relationship with the original pœm [...] A musical setting subdues the richness of multiple suggestions contained in a pœm while heightening certain of the pœm's images, connections and structural relationships. (Wenk 1976, p. 23)

Mais la fidélité au texte n'est pas la seule possibilité : rien n’empêche le musicien d'adopter une stratégie opposée et de soumettre plus ou moins le texte à une organisation proprement musicale, même si elle ne respecte pas l'organisation métrique et prosodique du poème. C'est précisément ce que montre l'exemple de «Lydia», qui, malgré les nombreuses «fautes» que l'on peut y relever, n'en est pas moins un authentique chef-d'œuvre. Plus encore, dès que l'on connaît la mélodie, on ne peut plus entendre le poème sans reprendre les inflexions suggérées par le traitement musical du texte, ce qui manifeste bien à la fois la liberté du musicien et la puissance de la musique qui impose en partie au moins sa loi au poème : je ne puis plus maintenant m'empêcher d'entendre

Le jour qui luit est le mei- lleur

//noire/croche/croche/noire pointée/croche // noire pointée/croche/blanche

avec sa nouvelle organisation d'accents, de durées et de hauteurs. Et, comme dans «Lydia», il arrive à Fauré de ne pas respecter ou même de contredire la prosodie du poème : c'est ce qui se passe dans Les Berceaux, sur un poème de Sully Prudhomme, où les premiers mots de chaque vers sont souvent des mots outils monosyllabiques (articles «le», relatif «que» etc.) que la musique place sur le temps fort et auxquels elle donne une durée importante. Dans une série d'articles, Pierre Fortassier a relevé un certain nombre de cas de ce genre (Fortassier 1955, 1960 et 1976), mais plutôt que d'y voir avec lui la volonté de corriger les insuffisances des poèmes qu'il mettait en musique, je crois qu'il s'agit de la marge de liberté dont disposent à la fois le diseur et le musicien lorsqu'ils «interprètent» un poème. Dans le cas des Berceaux, qui date d'une époque bien antérieure à L'Horizon chimérique (1879), il s'agit sans doute d'une intention figuraliste : «Lopposition entre les berceaux (la Terre, la Femme, la Vie) et les vaisseaux (la Mer, l'Homme, la Mort) dicte au musicien une formule 
d'accompagnement ingénieuse, associant tangage et bercement» (Nectoux 1995, p. 60) et cet accompagnement impose sa structure à l'ensemble du poème.

\section{UN POÈME ET QUATRE MÉLODIES}

Pour mieux comprendre la variété des choix qui s'ouvrent au compositeur à la fin du XIX siècle, je voudrais maintenant comparer les mélodies écrites par trois musiciens sur un même poème pour voir comment ils traitent les problèmes posés par la métrique et la prosodie. Il s'agit du poème de Verlaine «En sourdine» (Fêtes galantes, 1869) : il a été mis une première fois en musique par Debussy en 1882, puis par Debussy, Fauré et Reynaldo Hahn en $1891^{8}$, année de la mort de Rimbaud. Le poème est composé de cinq quatrains en vers de sept syllabes; les rimes, croisées (abab), ont la caractéristique exceptionnelle d'être toutes masculines. Comme il s'agit de vers courts sans hémistiche, il y a de nombreux cas dans lesquels les fins de vers ne coïncident pas avec les fins des unités syntaxiques. D'où la fréquence des phénomènes d'enjambements qui associent le plus souvent entre eux les deux premiers puis les deux derniers vers de la strophe, la césure strophique, marquée par une virgule, se situant à la fin du deuxième vers (strophes 1, 2, 3 et 5). Il n'y a pas par ailleurs de régularité dans la place des accents prosodiques à l'intérieur des vers. J'indique dans le tableau ci-dessous les fins de vers et les syllabes normalement accentuées ou accentuables à l'intérieur des vers, en rappelant qu'il existe toujours une marge d'interprétation. Je puis par exemple, au vers 2 , accentuer les syllabes «branches» ou "hau-tes», mais je puis aussi choisir de mettre en relief, pour des raisons qui peuvent être aussi bien d'ordre musical que poétique, le «ce» du vers 4 ou le «Et» du vers 13 comme le fait Debussy en 1882 en les plaçant sur le premier temps de la mesure (mesures 9 et 38 ). Je conserve dans le tableau la disposition suggérée plus haut : les traits doubles précèdent les syllabes métriques en fin de vers et les traits simples les autres syllabes normalement accentuables à l'intérieur des vers. Je ne m'intéresserai dans ce qui suit qu'à un aspect des relations entre vers et musique : la correspondance entre syllabes accentuables et temps forts. Il est clair que cette perspective ne donne qu'une idée partielle de ces relations, puisque le musicien peut marquer l'accent tonique par d'autres procédés (longueur, hauteur, harmonie, rythme), mais l'analyse montrera, je crois, l'importance de cet aspect.

\section{En sourdine}

(syllabes accentuables)

/Calmes dans le /demi-//jour

Que les /branches /hautes//font,

Pénétrons / bien notre a//mour

De ce si/lence pro//fond.

Fon/dons nos /âmes, nos //cœurs

8 Je reprends ici la comparaison esquissée par Arthur B. Wenk dans son beau livre Claude Debussy and the Poets (Wenk 1976, p. 38-42), en laissant de côté la mélodie de Raoul Laparra, composée beaucoup plus tard (1927). 
Et nos /sens extasi//és,

Parmi les /vagues lan//gueurs

Des /pins et des arbou//siers.

/Ferme tes /yeux à de//mi,

/Croise tes /bras sur ton //sein,

Et de ton /cœur endor//mi

/Chasse à ja/mais tout des//sein.

/Laissons-/nous persua//der

$\mathrm{Au} /$ souffle ber/ceur et //doux

Qui /vient à tes /pieds ri//der

Les /ondes de gazon //roux.

Et /quand, solen/nel, le //soir

Des /chênes /noirs tombe//ra,

/Voix de notre déses//poir,

Le rossi/gnol chante//ra.

Je commence par la mélodie de Reynaldo Hahn : ce qui la caractérise en effet, c'est une grande fidélité à l'organisation du poème. J'indique dans le tableau suivant les syllabes situées sur les temps forts dans la mélodie de Reynaldo Hahn selon les conventions précisées au-dessous (les barres inclinées correspondent aux barres de mesure) :

\section{En sourdine}

(R. Hahn)

/Calmes dans le demi-/jour Que les branches hautes /font/

/Pénétrons bien notre a/mour

De ce silence pro/fond/

/Fondons nos âmes, nos /cœurs

Et nos /sens extasi/és

Parmi les /vagues langueurs

Des pins et des arbou/siers/

/Ferme tes yeux à de/mi/

/Croise tes bras sur ton /sein/

/Et de ton cœur endor/mi

Chasse à ja/mais tout des/sein/

/Laissons-nous persua/der

Au souffle berceur et /doux

Qui vient à tes pieds ri/der

Les ondes de gazon /roux/

/Et quand, solen/nel, le /soir

/Des chênes noirs tombe/ra

/Voix de notre déses/poir

Le rossi/gnol chante/ra/ 


\section{Symboles}

$\begin{array}{ll}\text { jour } & \text { syllabe sur le } 1^{\text {er }} \text { temps de la mesure à } 4 \text { temps } \\ \text { Voix } & \text { prolongation d'une syllabe en syncope sur le } 1^{\text {er }} \text { temps } \\ \underline{\text { bien }} & \begin{array}{l}\text { syllabe sur le } 3^{\text {eme }} \text { temps de la mesure } \\ \text {-mour }\end{array} \\ \text { syllabe sur la partie forte du } 1^{\text {er }} \text { temps }\end{array}$

Les strophes sont séparées par des silences plus longs que ceux qui séparent les vers. En ce qui concerne les fins de vers, il y a 16 cas sur 20 où la syllabe finale est située sur le premier temps de la mesure à quatre temps. Au vers 7 (mesure 16), la dernière syllabe n'est pas soulignée par la musique, à cause sans doute du lien syntaxique fort qui unit le mot «langueurs» à son complément «des pins»; par ailleurs la mesure s'organise en deux triolets correspondant au premier et au troisième temps. Au vers 13, la syllabe "soir» se situe sur le troisième temps de la mesure et se trouve soulignée par le trait de «tenuto». À la fin des vers 3 et 15 (mesures 9 et 30), le premier temps est divisé en deux croches qui correspondent à la dernière syllabe du vers et à la première du vers suivant, les deux vers étant étroitement liés du point de vue syntaxique : «Pénétrons bien notre amour / de ce silence profond »; «Qui vient à tes pieds rider / Les ondes de gazon roux".

Â l'intérieur des vers, les accents prosodiques normaux sont souvent marqués par des moyens musicaux divers. Les syllabes correspondantes peuvent se trouver soit sur le premier temps, directement («sens», au vers 6, mesure 14) ou grâce à une syncope («Calmes», au vers 1, mesures 4-5), soit sur le troisième temps de la mesure, qui porte un accent secondaire (" Calmes» au vers 1, «bien», «silence» aux vers 3 et 4 , mesures 8 et 9). Un certain nombre de mesures commencent par un demi-soupir, ce qui permet précisément de faire tomber la syllabe accentuée sur le troisième temps (vers 3, 5 ou 11). Dans les vers 9, 10 et 12, la présence d'un impératif en tête de vers entraîne deux accents internes, l'un sur le premier temps de la mesure (mesures 19 et 21) ou le troisième (mesure 24) et l'autre sur le troisième temps (mesures 19 et 21) ou le premier de la mesure suivante (mesure 25). Le parallélisme linguistique des vers 9 et 10 est accompagné et souligné par la musique (mesures 19-20 et 21-22).

Comme on le voit, la structure musicale suit jusque dans le détail la métrique et la prosodie du poème, ce qui correspond sans doute à la fois à une exigence du musicien et à la demande du public. Il s'agit de chanter des vers sans rien sacrifier de leur organisation propre de sorte que la transition de la récitation au chant s'opère sans difficulté : la musique vient ici clairement s'additionner au poème, l'illustrer sans trop le modifier. Si l'on ajoute la facilité technique de la partie de piano et le caractère élémentaire de l'harmonie, on comprend à la fois le public visé et le succès de ces mélodies : les Chansons grises sur des poèmes de Verlaine dont fait partie «En sourdine» répondaient aux capacités et aux goûts de chanteuses et chanteurs amateurs à la recherche d'un répertoire «moderne» et accessible.

En ce qui concerne la construction générale de la mélodie, il est intéressant de noter la réapparition, avant le début de la cinquième et dernière strophe, de l'accompagnement de piano du début, c'est-à-dire des deux premières. Il s'agit 
d'une technique d'encadrement qui reprend, pour le piano, la forme du lied varié (ABA') et que l'on retrouvera chez Debussy.

Voyons maintenant comment procède Debussy en 1882. Voici d'abord le tableau correspondant aux syllabes situées sur des temps forts dans la mélodie de Debussy :

\section{En sourdine}

(Debussy I)

/Calmes dans le /demi-jour

/Que les branches hautes /font/

Pénétrons bien notre a/mour

De /ce silence pro/fond/

/Fondons nos /âmes, nos /cœurs

Et nos sens exta/siés

Parmi les /vagues lan/gueurs

Des /pins et des arbou/siers/

/Ferme tes yeux à de/mi

Croise tes /bras sur ton /sein/

IEt de ton cœur endor/mi

Chasse à ja/mais tout des/sein/

/Laissons-nous persua/der

$\mathrm{Au} /$ souffle berceur et /doux

Qui /vient à tes pieds ri/der

Les/ondes de gazon/roux/

/Et quand, solen/nel, le /soir

Des chênes (noirs) 9 tombe/ra,

/Voix de notre déses/poir

Le rossi/gnol chante/ra/

\section{Symboles}

Calmes syllabe sur le $1^{\text {er }}$ temps de la mesure à 3 temps

souffle prolongation d'une syllabe en syncope sur le $1^{\text {er }}$ temps

demi syllabes sur les deux croches divisant le $1^{\mathrm{er}}$ temps

À cette époque, Debussy se situe encore dans le cadre de la carrure traditionnelle : chaque groupe de deux vers correspond à un ensemble de 4 mesures. Par ailleurs, il marque les fins de strophes par des silences de la voix plus ou moins longs : fin de la première strophe à la mesure 10 ( 2 temps), fin de la deuxième à la mesure 18 ( 2 temps), fin de la troisième à la mesure 26 ( 1 temps) et fin de la quatrième aux mesures $34-37$ ( 1 temps puis 3 mesures). En ce qui concerne la dernière syllabe des vers, elle se situe dans 17 cas sur 20 sur le premier temps de la mesure. Dans les trois exceptions (vers 1, 5 et 17 aux mesures 4, 13 et 40),

9 Dans les éditions à ma disposition, le mot «noir» ne figure pas, ce qui rend le vers faux, alors qu'il figure dans la mélodie de 1891. On peut se demander si Debussy ne l'a pas supprimé pour conserver une des organisations rythmiques dominantes de la mélodie, la mesure composée de 3 groupes de 2 croches. 
le premier temps est divisé en deux croches et ce n'est qu'à la fin du vers 4 que la dernière syllabe («jour») ne se situe pas sur le temps fort. Quant aux accents à l'intérieur des vers, un certain nombre d'entre eux se trouvent aussi sur le temps fort de la mesure, bien qu'il y ait quelques mises en relief musicales qui ne correspondent pas à l'accentuation normale : le «ce» du vers 4 (mesure 9) ou la première syllabe de "Fondons" à la mesure 11. On peut remarquer au passage que, pas plus en 1882 qu'en 1891, Debussy n'opère la diérèse «extasi-és», qu'opèrent aussi bien Fauré que Reynaldo Hahn, ce qui rend le vers faux avec 6 au lieu de 7 syllabes. Sans vouloir en tirer une conclusion définitive, on peut se demander si cet indice ne tendrait pas à montrer que Debussy ne récite pas les vers avec autant de soin. D’une façon générale cependant, on constate qu'en particulier en ce qui concerne les syllabes métriques qui marquent les fins de vers, Debussy témoigne d'une non moins grande fidélité que Reynaldo Hahn à la versification, mais cette fois dans le cadre d'une mesure à trois temps et non plus à quatre. Les différences entre les deux mélodies me semblent surtout résider dans le rôle du piano, beaucoup plus autonome et varié chez Debussy : c'est lui qui impose son organisation.

Quelle est en effet la forme de la mélodie? On ne peut qu'être frappé, dans la partie de piano, par les parallélismes entre le début, c'est-à-dire les mesures 1 à 26 correspondant aux trois premières strophes et les mesures 38 à 54 correspondant à la cinquième et dernière. Les mesures 38 , 39 et 40 présentent trois fois la figure déjà redoublée aux mesures 11 et 12, tandis que les mesures 42 à 45 reprennent les mesures 19 à 22 avec, dans les deux cas, parallélisme entre le chant et la partie de soprano du piano. C'est le même parallélisme qui apparaît aux mesures 46 à 48 -où sont répétés les deux derniers vers - qui reprennent, avec quelques variations, les mesures 23 à 25 . Enfin les mesures finales, 49-50 et 51-52, reprennent les duplications initiales des mesures 1-2, 3-4 et 5-6 et servent ainsi de formule d'encadrement pour la mélodie. On voit donc qu'il s'agit d'une variation sur la forme $\mathrm{ABA}^{\prime}$ : A comprend les strophes un à trois, mesures 1 à $26, \mathrm{~B}$ comprend la quatrième strophe, mesures 27 à 37 , et A' la strophe cinq, mesures 38 à 54 .

Lorsque Debussy reprend le poème en 1891, il semble ne rien garder de la première version. Voici le tableau correspondant à la deuxième mélodie de Debussy :

\section{En sourdine}

(Debussy II)

/Calmes dans le /demi-jour

Que les /branches hautes font

Pénétrons / bien notre a/mour

De ce si/lence profond/

/Fondons nos /âmes, nos cœurs

Et nos /sens extas/iés

Parmi les /vagues langueurs

Des pins et /des arbousiers/

/Ferme tes yeux à de/mi 
Croise tes /bras sur ton /sein

Et de ton /cœur endor/mi

Chasse à jamais tout des/sein/

/Laissons-nous persua/der

$\mathrm{Au} /$ souffle berceur et doux

/Qui vient à tes pieds ri/der

Les ondes de gazon /roux/

/Et quand, solen/nel, le soir

Des chênes /noirs tombera/

/Voix de notre déses/poir,

Le rossi/gnol chante/ra/

\section{Symboles}

bien syllabe sur le $1^{\text {er }}$ temps de la mesure à 3 temps

si/lence, demi, vagues langueurs syllabe(s) sur la partie forte ( $1^{\text {ère }}$

croche), sur les 2 croches ou sur un triolet du $1^{\mathrm{er}}$ temps

Debussy continue à marquer par des silences la fin de chaque strophe : ici, il s'agit chaque fois d'une mesure. La longueur de chaque strophe est à peu près constante : 6 mesures exactement pour la première, la deuxième et la quatrième, 7 pour la troisième et la cinquième. Une des différences les plus significatives avec la version précédente est qu'il y a maintenant beaucoup moins de syllabes finales de vers qui correspondent aux temps forts de la mesure. Au lieu des 17 cas sur 20 de la première version, il n'y en a plus maintenant que 9, avec un cas où le premier temps est divisé en deux croches (vers 15, mesure 30). Il n'y a par ailleurs qu'un petit nombre d'accents internes qui correspondent à des temps forts : vers 3, 5, 10 et 11, 18 et 20. Le plus souvent le temps fort est divisé en deux croches ou en un triolet et les syncopes jouent un rôle essentiel aussi bien pour la voix que pour la partie de piano.

Si donc Debussy respecte l'organisation strophique en la soulignant par une partie de piano qui, sauf au début, change entre chaque strophe, il n'est plus aussi étroitement fidèle à l'organisation métrique et accentuelle des vers. La voix entre dans une dialectique complexe avec le piano, qui joue un rôle beaucoup plus actif dans la construction de l'œuvre. Le musicien ici ne se récite pas le poème jusqu'à ce qu'il ait trouvé l'expression qui lui convient, il a une «idée» musicale plus ou moins indépendante de la lettre du poème. Un exemple caractéristique des contraintes auxquelles l'idée musicale soumet le texte est fourni par la fin du vers 2. Dans la mesure 6 figurent les 8 syllabes «branches hautes font, pénétrons» : «font», qui marque la fin du vers, est suivi d'une virgule, mais correspond ici, après une série de croches, à la première d'un groupe de quatre doubles-croches qui ne se distingue des suivantes que par l'absence de tenuto. Il vaut la peine de remarquer que, dans à peu près toutes les interprétations de la mélodie, la chanteuse ne peut s'empêcher de marquer la fin de vers et la virgule, auxquelles rien ne correspond dans la partition. De même, à la mesure 11, Debussy fait correspondre aux deux syllabes du mot «Fondons», la première non accentuée et la deuxième accentuée, une 
noire puis une croche, sans que rien ne vienne par ailleurs, pas plus ici que dans l'exemple précédent, souligner la syllabe accentuée. Dès le début, la poésie semble bien soumise aux nécessités de l'organisation musicale, c'est-à-dire au jeu de duplications engendré par les quatre premières mesures de l'accompagnement : c'est ce que montrent par exemple les trois syllabes de la mesure 7 («bien no-tre a »-mour) entre lesquelles viennent s'insérer les trois notes par lesquelles a commencé le piano.

Quelle est la forme de cette mélodie? Sans entrer dans le détail des duplications qui unifient les différentes parties de la mélodie, il est clair que la cinquième et dernière strophe ramène, variées, les figures des mesures 1 et 2 (mesures 32-34) qui reviendront à la fin de la mélodie (mesures 39-42). Il s'agit donc d'une forme $A B A$ ', avec A correspondant aux deux premières strophes (mesures 1-17), B aux troisième et quatrième strophes (mesures 18-31) et $A^{\prime}$ à la cinquième et dernière (mesures 32-43).

Arrivons-en enfin à Fauré, dont le tableau suivant indique les syllabes situées sur des temps forts :

\section{En sourdine}

(Fauré)

/Calmes dans le demi-/jour

Que les branches hautes /font/

Pénétrons / bien notre amour/

De ce silence pro/fond.

Mêlons nos /âmes, nos /cœurs

Et nos sens extasi/és

Par/mi les vagues lan/gueurs

Des /pins et des arbou/siers/

/Ferme tes yeux à demi/

/Croise tes bras sur ton sein/

/Et de ton cœur endor/mi

Chasse à ja/mais tout des/sein/

/Laissons-nous per/suader

$\mathrm{Au} /$ souffle berceur et /doux

Qui /vient à tes pieds ri/der

Les ondes des /gazons/roux/

/Et quand, solen/nel, le soir

Des /chênes noirs tombe/ra/

/Voix de notre déses/poir/

Le /rossignol/chante/ra.

\section{Symboles}

Calmes syllabe sur le $1^{\text {er }}$ temps de la mesure à 4 temps

cœurs syllabe prolongée en syncope sur le $1^{\text {er }}$ temps

amour syllabe sur le $3^{\text {ème }}$ temps de la mesure

vagues syllabe prolongée en syncope sur le $3^{\text {ème }}$ temps

Parmi les syllabes sur les deux parties du $1^{\text {er }}$ temps ( $1^{\text {ère }}$ et $2^{\mathrm{e}}$ croche) 
On peut tout d'abord noter que Fauré témoigne ici encore de "préoccupations extrêmement subtiles dans le domaine de la sonorité» (Nectoux 2008, p. 448). Il apporte en effet deux modifications au texte de Verlaine. Au vers 5, il substitue au verbe "Fondons», qui le gêne sans doute à cause de la succession de ses deux voyelles nasales, le verbe «Mêlons». Au vers 16, il remplace le syntagme «Les ondes de gazon roux» par «Les ondes des gazons roux» pour éviter la succession de deux «e muets». En ce qui concerne les syllabes métriques, 15 finales de vers sont situées sur le premier temps de la mesure à quatre temps et 5 sur le troisième, avec plusieurs syllabes qui sont à la fois sur le troisième et prolongées sur le premier de la mesure suivante («yeux», «bras», « roux », rossi «gnol»), c'est-à-dire que toutes les fins de vers correspondent à un temps fort. Pour les accents prosodiques à l'intérieur des vers, il n'y a que deux vers dans lesquels ils ne sont pas situés sur le premier ou le troisième temps. Il s'agit du vers 2, mesure 4, où l'accent qui porte sur la syllabe finale de groupe «hau-tes» est indiqué par l'allongement de la note correspondante, une croche pointée après 4 croches et avant une double-croche, et du vers 6 , mesure 11, où la syllabe «ex-ta-si-és» est soulignée par un allongement semblable. Une des séquences de durées les plus fréquentes est constituée d'une croche pointée suivie d'une double-croche avant une noire ou valeur plus longue située sur un temps fort. On les retrouve aux mesures 3, 4, 7, 8, 9 etc. et cet «allongement de l'antépénultième» signalé par Pierre Fortassier (Fortassier 1976, p. 268) correspondant à des groupes accentuels du type «demi-jour», «hautes font», "notre a-(mour)», «(silen)-ce profond», qui soulignent ainsi les rimes toutes masculines du poème ${ }^{10}$.

L'organisation globale de la mélodie correspond à une variante de la forme ABA' : A correspond aux deux premières strophes, $B$ aux deux suivantes, avec l'apparition d'une figure de triolet aussi bien au chant qu'au piano, et A' à la cinquième et dernière strophe, avec la reprise à peine variée du début du chant (les mesures 33-36 reprenant le profil mélodique des mesures 2-5). Par ailleurs, la mélodie entière est organisée par la montée qui mène du sol 3 initial à la tonique, $m i$ bémol 4, qui n'apparaît qu'à la fin de la mélodie, à la mesure 42, et en constitue le sommet (Orledge 1983, p. 81). On peut ajouter qu'il n'y a guère ici de figuralisme, alors que la deuxième mélodie de Debussy est en grande partie organisée autour d'un motif musical qui évoque le chant du rossignol (Orledge 1983, p. 81).

\section{Pó́SIE ET MUSIQUe EN 1900}

Si l'on compare maintenant le traitement du poème dans les quatre mélodies, il est clair, comme le montrent les «transcriptions» métrico-rythmiques que nous avons proposées, qu’elles se rangent en deux groupes : la mélodie

10 Ce n'est pas ici le lieu de discuter la théorie de la versification française soutenue par Roger Pensom, qui propose dans un de ses ouvrages une analyse du poème de Verlaine et de sa mise en musique par Fauré (Pensom 1998, p. 109-116). Mais il vaudrait la peine de reprendre son argumentation, discutée par Dominique Billy (Billy, 2003), à laquelle la mélodie de Fauré pourrait donner quelques arguments. 
de Debussy composée en 1891 s'oppose aux trois autres. Même s'il souligne encore musicalement un certain nombre de fins de vers, en particulier pour la troisième et la dernière strophes, Debussy, en 1891, ne fait pas du respect de la structure du poème un impératif musical : ce sont au contraire les idées musicales qui imposent leurs contraintes au poème. N'en donnons qu'un exemple supplémentaire : alors que Fauré et Reynaldo Hahn traduisent musicalement le parallélisme linguistique des vers 9 et 10, Debussy n'essaie pas davantage de le mettre en valeur en 1891 qu'en 1882.

On aboutit à des conclusions analogues si on se livre à la comparaison réalisée par Madame Beltrando-Patier dans sa thèse entre les deux mélodies de Fauré et Debussy composées sur le poème de Verlaine «Il pleure dans mon cœur ...» (Beltrando-Patier 1981, p. 333-352). La mélodie de Fauré, intitulée «Spleen », date de 1888, tandis que celle de Debussy doit dater des années 18861887. Il s'agit de comparer les courbes intonatives de la diction poétique et les courbes musicales correspondantes. La méthode n'a rien de scientifique et n'a qu'une valeur indicative, mais fait bien ressortir la différence des perspectives :

En première lecture, on constate immédiatement l'individualisation de la courbe mélodique de Debussy. Si celle de Fauré présente quelques divergences par rapport à l'harmonie des deux courbes intonatives, il sera toujours possible de les motiver [...] et leur apparition est très épisodique. Dans le cas de Debussy, au contraire, la part d'insoumission au verbe est prépondérante et fait ressortir la soumission fauréenne (Beltrando-Patier 1981, p. 335).

Fauré représente bien un pôle dans la fidélité à l'organisation du vers :

Sa déclamation, tout ensemble d'une convenance et d'une grâce exquise, se montre beaucoup plus exacte que chez les musiciens de la même génération; [...] La déclamation fauréenne, toujours mélodique, parvient à surprendre la musique fugace du langage français, moins apparente que celle, par exemple, du langage italien, mais combien plus délicate et partant plus précieuse! (Ravel 1922, p. 26).

C'est qu'il se situe au terme d'une évolution. Si, depuis au moins Gounod, les musiciens tendaient à respecter de plus en plus les caractéristiques propres du vers (Noske 1954, p. 147-151), ce respect conduit à une conséquence paradoxale, que résume parfaitement Frits Noske : «on respecte tant le rythme poétique, qu'on hésite à mettre en musique des vers réguliers» (Noske 1954, p. 59). C'est bien ce dont témoignent les réponses des musiciens à l'enquête menée en février-mars 1911 par la revue Musica : «Sous la musique que faut-il mettre? De beaux vers, de mauvais, des vers libres, de la prose?». Pour Ravel, le vers régulier

peut permettre de fort belles choses, à condition que le compositeur veuille s'effacer entièrement derrière le poète et consente à suivre ses rythmes pas à pas, cadence par cadence, sans jamais déplacer un accent ni même une inflexion. En un mot, si le musicien veut travailler sur des vers réguliers, 
sa musique devra simplement souligner le poème, le soutenir, mais elle ne pourra rien en traduire, rien y ajouter.

C’est pour la même raison que Debussy récuse la poésie régulière : «Les vers classiques ont une vie propre, un "dynamisme intérieur", pour parler comme les Allemands, qui n'est pas du tout notre affaire.»C'est pourquoi tous deux préfèrent une prose au rythme plus libre : «Avec la prose rythmée, on est plus à son aise, on peut mieux se tourner dans tous les sens» (Debussy);

La prose est quelquefois très agréable à mettre en musique et il est des circonstances où elle est merveilleusement appropriée au sujet. Ainsi, j'ai pris plusieurs des Histoires Naturelles de Jules Renard; c'est délicat, rythmé, mais rythmé tout autrement que les vers classiques (Ravel) (cités dans Noske, 1954, p. 59-60).

Et, en répondant à la même enquête, Fauré lui-même ne se montrait pas insensible aux possibilités de la prose : «Tandis qu’une prose rythmée, si elle est fluide, harmonieuse, pourra servir de thème, merveilleusement» (cité dans Nectoux 1995, p. 104). N'oublions pas en effet qu'il venait de mettre en musique les vers beaucoup plus libres de Charles Van Lerberghe (La Chanson d'Ève op. 95, composée de 1906 à 1910) auxquels il allait encore s’adresser pour Le Jardin clos op. 106 (1914).

La fin du XIX et le début du XX ${ }^{\mathrm{e}}$ siècles apparaissent ainsi comme une époque de rupture aussi bien dans l'évolution de la poésie que dans les relations entre la poésie (et plus généralement le langage) et la musique. Il y a d'un côté «crise de vers» (Mallarmé 1897). Hugo avait bien déjà «desserré» - pour reprendre le mot de Mallarmé - les contraintes du vers et de l'alexandrin en particulier en donnant autant ou plus d'importance aux accents internes qu'aux accents proprement métriques à la césure et à la fin du vers (il s'agit du fameux trimètre romantique), mais le monument était encore solide et les règles fondamentales restées intactes. Et voici que Rimbaud, dans une lettre du 25 août 1870 à Georges Izambard, cite un vers des Fêtes Galantes, parues l'année précédente, qui lui semble remarquable parce que l'hémistiche se situe à l'intérieur d'un mot («Et la tigresse épou-vantable d'Hyrcanie»). Peu de temps après (en 1870, 1871 ou 1872 ?), il écrit le poème "Qu'est-ce pour nous, mon cœur ...», dans lequel il viole systématiquement les règles concernant la césure (Roubaud 1978, p. 19-35). Lorsque le poème paraît en 1886 dans la revue La Vogue en même temps que Les Illuminations et les premiers «vers libres» de Gustave Kahn et de Jules Laforgue, la rupture est accomplie. On est entré dans une "période 'tourbillonnaire' destinée à se prolonger très avant dans le $\mathrm{XX}^{\mathrm{e}}$ siècle» (Roubaud 1978, p. 19). C'est-à-dire que ce qu'on appelle poésie s'étend maintenant sur un continuum qui va de la versification la plus traditionnellement stricte c'est le cas de L'Horizon chimérique - jusqu'à la prose en passant par toutes les formes possibles de vers «libérés».

Le musicien de son côté dispose ainsi d'une beaucoup plus grande liberté dans le choix des poésies qu'il veut mettre en musique : c'est bien ce que montrent les réponses à l'enquête de Musica que j'ai citées. Mais en même temps 
il est de plus en plus conscient des libertés qu'il peut prendre par rapport à la métrique et à la prosodie : c'est ce dont témoigne la comparaison entre les mélodies de Reynaldo Hahn, Fauré et Debussy. Il suffit de rapprocher du jugement de Ravel cité tout à l'heure les pages que Marcel Beaufils consacre à Fauré dans son ouvrage Musique du son, musique du verbe, paru en 1954, pour constater l'ampleur de la mutation : «Pour ce qui nous regarde, Fauré, dans la plupart des cas, est victime d'une acceptation trop passive du mètre verbal». Et il précise : «Si grande est la manie, chez Fauré, de palper à chaque instant le corps du vers alexandrin» que «l'ombre de la structure poétique se fait sentir sur la formulation mélodique» (Beaufils [1954] 1994, p. 135-136).

Fauré et Debussy se situent ainsi sur les deux versants opposés d'une même ligne de fracture : tandis que Fauré respecte fidèlement la métrique et la prosodie du vers récité, Debussy soumet le vers à des impératifs musicaux et en particulier au jeu des duplications. Sa prosodie n'est pas, comme on le dit trop souvent, plus fidèle au rythme de la parole, c'est une prosodie artificielle, mais extrêmement suggestive et efficace, une prosodie stylisée. Je la comparerais volontiers à la stylisation du langage paysan à laquelle se sont livrés Ramuz ou Giono. Il ne s'agit évidemment pas de condamner l'un ou l'autre ou de prétendre qu'une solution est supérieure à l'autre et Schœnberg avait raison de se moquer des critiques qui relevaient des «fautes de déclamation chez Wagner» (Schœnberg 1984, p. 143). Il est légitime de parler de «fautes» de prosodie dans les premières mélodies de Fauré parce que lui-même les a implicitement reconnues en modifiant son traitement des syllabes accentuées et non accentuées, mais il n'y aurait évidemment aucun sens à parler de "fautes» dans la prosodie de Debussy. Inversement, il faut éviter de jouer sur les deux tableaux en créditant l'auteur de Pelléas d'un plus grand respect du rythme de la parole, un peu comme les critiques d'art se sont ingéniés à justifier le cubisme en soutenant qu'il était fidèle à la vision des multiples aspects d'un même objet : pourquoi ne pas simplement reconnaître l'originalité et la beauté de cette création d'une nouvelle stylisation de la parole chantée? Il vaudrait d'ailleurs la peine de s'interroger, plus qu'on ne le fait habituellement, sur les sources et le développement de cette nouvelle «diction » musicale, qui correspond sans doute à de nouvelles formes de diction poétique. Peut-être faudrait-il aller voir du côté de Sarah Bernhardt, dont la «mélopée uniforme » à laquelle faisait allusion Proust aurait pu servir d'inspiration à Debussy.

Il n'y a cependant aucune raison de suivre Schœenberg lorsqu'il affirme que le respect de la déclamation, du tempo et de la dynamique du texte récité «belongs to the same stage of primitive imitation of nature as the copying of a model» (Schœnberg 1984, p. 145). Il est vrai que ce qu'il appelle correspondance «externe» entre texte et poésie ne garantit pas la réussite de l'œuvre, mais l'absence ou le rejet de toute correspondance ne la garantit pas davantage. C'est qu'il existe une tension constante et l'on pourrait dire constitutive entre les deux formes symboliques, à la fois proches par certaines de leurs caractéristiques mais fondamentalement distinctes, ne serait-ce que par la présence dans le langage d'une sémantique de type conceptuel. Rien donc n'oblige la musique à respecter les propriétés du langage qui sont les plus proches de ses 
propres caractéristiques, mais rien non plus n'oblige à n'en pas tenir compte ou à en prendre le contre-pied. Il convient donc de reconnaître la légitimité des deux approches, qui coexistent et se succèdent tout au long de l'histoire de la musique européenne, comme lorsqu'on passe du motet pluritextuel au «stile rappresentativo » de la Camerata fiorentina. On est, au début du XXe siècle, au commencement d'un nouveau cycle qui conduit au Sprechgesang et au traitement qu'un Berio ou un Boulez imposent au langage : on découvre alors les possibilités expressives d'une parole coupée de toute signification conceptuelle et traitée comme matériau musical dont on ne respecte plus l'organisation propre tout en conservant l'aura d'une communication indéchiffrable. Mais le cycle s'est sans doute achevé avec la postmodernité, dans laquelle la voix retrouve un statut et des modes de présentation qui renouent avec la tradition et entendent lui rendre toute sa densité sémantique.

\section{Pó́sie et langage musical}

Le rôle de la poésie dans les mélodies s'arrête-t-il ici? On pourrait en effet penser que, au-delà de la métrique et de la prosodie, le langage musical de Fauré est le même que dans ses autres œuvres. Il ne faut pourtant pas oublier que la mélodie, née du poème, en est aussi la mise en valeur. Il est alors légitime de se demander si l'influence du poème ne s'étend pas à d'autres dimensions de son langage musical. Je voudrais donc, en continuant à explorer le rôle du poème dans la composition d'une mélodie, m'intéresser à quelques aspects du langage de Fauré pour lesquels on peut mettre en évidence des relations plus ou moins étroites entre musique et poésie. J'en retiendrai quatre : le soulignage du texte par l'harmonie, la mise en relief du rythme de la parole par le jeu de la pulsation, la «mélodie continue» et enfin le problème du figuralisme et des correspondances «sémantiques» entre texte et musique.

\section{Harmonie : le soulignage par l'harmonie}

Je voudrais partir d'une profonde remarque faite par Madame Dommel-Diény à propos de la première mélodie de L'Horizon chimérique, «La mer est infinie»:

Nous allons voir en effet tous les mots significatifs du texte soulignés soit par un dessin mélodique dissimulé dans le contrepoint, soit par un ornement, un accent, ou un mouvement harmonique, sans que cesse pour autant cette 'mobilité immobile' de la mer qui justifie un mode d'écriture permanent de la première à la dernière mesure (Dommel-Diény 1967, p. 43).

Je vais me borner à envisager quelques cas de mise en relief de certains mots, à la fois importants et situés à des «places marquées» du poème (fins d'hémistiche, de vers et de strophe), sinon par une véritable modulation du moins par un changement harmonique plus ou moins localisé.

Dans cette première mélodie en ré majeur, à la mesure 4, l'adjectif «fous", mot à la rime et en même temps sémantiquement très fort, est souligné par la disparition des dièses dans un accord $f a$ bécarre-la-do bécarre (accord du IIIème 
degré abaissé), mais celui-ci s’enchaîne aussitôt au Ve degré en rétablissant les dièses à la mesure suivante. Il en est de même aux mesures 6 et $7:$ le groupe de mots «en battant les falaises» est mis en relief par l'abandon momentané de ré majeur avec disparition des dièses et apparition du si bémol, mais la tonalité de référence réapparaît à la mesure 8 . À la mesure 10, la fin du vers «comme des oiseaux soûls", qui marque en même temps la fin de la première strophe, voit apparaître un sol dièse (la majeur) qui disparaît à la fin de la mesure suivante. La partie la plus «active» du point de vue harmonique correspond à la deuxième strophe et aux vers «La brise les agite et les roule en ses plis; / Jouant dans le sillage, ils feront une escorte / Aux vaisseaux que mon cour dans leur fuite a suivis». Les mesures 15-16 voient successivement apparaitre sol dièse, mi dièse, la dièse et ré dièse qui disparaissent à la mesure suivante en même temps que le $f a$ dièse et le sol dièse, mais la tonalité de ré majeur réapparaît aux derniers mots de la strophe (mesure 20). À la mesure 25 enfin, le mot "pleurs», qui est aussi fin de vers, est souligné par l'apparition d'un sol dièse qui disparaît dès le début de la mesure suivante. Il est clair que l'on peut difficilement parler ici de véritables modulations, mais plutôt, pour reprendre les expressions de Madame Dommel-Diény, d' «inflexions modulantes» ou de "jeux modulants», qui demeurent des «allusions» et qui résultent souvent de la rencontre de lignes mélodiques indépendantes (Dommel-Diény 1967, p. 46-48).

Des phénomènes comparables peuvent être mis en évidence dans la troisième mélodie du recueil, «Diane, Séléné ... », en mi bémol majeur. La fin du premier vers, «beau métal», est soulignée par l'altération passagère du la bémol en la bécarre durant deux temps de la mesure 4. Les mesures 5-8, pour illustrer les deux vers "Qui reflètes vers nous, par ta face déserte, / Dans l'immortel ennui du calme sidéral», passent à do bémol, qui, à la mesure 7, devient si par enharmonie. La fin de la première strophe, «dont nous pleurons la perte», coïncide avec la cadence modale qui mène à $u t$ mineur. À la mesure 12, le verbe «je t'en veux» est souligné par l'apparition, sous la syllabe "veux», du la bécarre qui marque le passage à la tonalité de $s i$ bémol, tandis que le mot placé à la fin du vers suivant, "âmes», coïncide avec le très bref passage à sol mineur (mesure 15). À la mesure 17 enfin, les mots « et toujours agité » coïncident avec le passage à la tonalité de sol bémol, qui disparaît avec le mot "paix» (sol bécarre) pour revenir à la tonalité de référence de mi bémol.

Précisons bien notre propos. Il ne s'agit pas de dire que Fauré construit le plan harmonique de ses mélodies à partir seulement de la structure et du sens de la poésie. Les exemples que je viens de donner montrent en revanche que les données poétiques sont des facteurs qui entrent en jeu pour organiser cette construction. Mais ce n'est qu'un aspect des relations entre texte et développement harmonique de la mélodie. Dans d'autres cas en effet, ce n'est pas seulement des mots qui reçoivent un traitement particulier, ce sont des vers, des strophes qui déterminent en partie au moins ce développement.

Dans la quatrième mélodie, "Vaisseaux, nous vous aurons aimés ...», la première strophe commence en ré et finit en ré après une brève suggestion de modulation au ton relatif $s i$ qui coïncide avec la fin du $2^{\mathrm{e}}$ vers « ... est parti sur la mer» (apparition du la dièse). La deuxième strophe commence aussi en ré, 
passe à sol avec apparition du do bécarre à la mesure 11 («ren-dus»), puis à la mineur (apparition du $f a$ bécarre) à la mesure 15 («nous ne pouvions gar-der»). Elle revient à sol à la mesure 16 (réapparition du fa dièse), terminant sur un accord $f a$ dièse-ré-la avant la réapparition du do dièse et le retour à ré à la fin de la même mesure qui coïncide avec le début de la $3^{\mathrm{e}}$ strophe. Celle-ci, commençant donc en ré, touche successivement à $f a$ dièse mineur à la mesure 19 (apparition du sol dièse), à ut dièse mineur à la mesure 20 (apparition du sol dièse, du ré dièse et du si dièse) et enfin à sol mineur à la mesure 22 avant de retrouver le ré initial à la mesure 25. On le voit, chaque strophe commence et finit dans la tonalité de base, après de brèves «inflexions modulantes» (Dommel-Diény 1967, p. 48) qui correspondent dans chaque strophe à une espèce d'extension de cette tonalité par l'intégration de tonalités apparentées : le relatif $s i$ dans la première strophe, la mineur et sol dans la deuxième et $f a$ dièse dans la troisième (Dommel-Diény 1967, p. 66). On retrouve le même retour à la tonique à la fin de chaque strophe dans la deuxième mélodie du recueil, "Je me suis embarqué ... », bien que cette mélodie se caractérise par une " extraordinaire mobilité harmonique» (Dommel-Diény 1967, p. 49). On voit ainsi que la strophe est une unité poétique qui constitue un facteur déterminant de l'organisation harmonique de la mélodie.

\section{Rythme : le jeu de la pulsation et de la parole}

Lorganisation rythmique des mélodies de Fauré apparaît comme tout à fait traditionnelle si on la compare par exemple à celle de Debussy, ce que souligne l'accompagnement au piano. Fauré est en effet resté fidèle tout au long de sa carrière à deux types d'accompagnement (Orledge 1983, p. 263-264). Il utilise d'une part un accompagnement de type choral, avec une succession régulière d'accords, un par temps, qui correspond de façon privilégiée à des poèmes que l'on a pu qualifier de contemplatifs. La troisième mélodie de L'Horizon chimérique, «Diane, Séléné ... », vient ainsi «clore l’incomparable ensemble de mélodies contemplatives de Fauré : Le Secret, Le Parfum impérissable, Ô Mort, poussière d'étoiles (de la Chanson d'Ève), Dans la Nymphée et Inscription sur le sable (du Jardin clos)» (Nectoux 1995, p. 210). Il utilise d'autre part le plus souvent un accompagnement reposant sur des figures arpégées, que l'on retrouve, sous des formes différentes, dans les trois autres mélodies du recueil. Dans «La mer est infinie», les accords brisés répartis entre les deux mains imposent du début à la fin le flot régulier de leurs douze doubles-croches par mesure.

Dans les deux cas, le rythme semble donc parfaitement régulier et même monotone. Mais il importe en fait de distinguer deux niveaux dans le rythme des mélodies, comme d'ailleurs dans toute la musique de Fauré. L’accompagnement établit une pulsation régulière, mais c'est précisément cet appui de la pulsation régulière qui permet tous les jeux de rythmes et d'accents :

[...] il faut souligner que c'est la pulsation qui est régulière chez Fauré et que c'est dans le cadre de ce battement régulier qu'il organise les rythmes et diversifie les accents, car le cantabile fauréen n'est pas réitération amorphe, il s'anime d'accents déplacés, de rythmes contrariés, et l'on peut 
même avancer que le musicien pratique une sorte d'art du décalage, particulièrement sensible dans son écriture pianistique, si proche en cela, et par sa difficulté même, de celle de Robert Schumann ou Johannes Brahms (Nectoux 2008, p. 317).

Et l'on a souvent souligné le parallélisme avec le traitement fauréen de l'harmonie, dans laquelle les «jeux modulants» se détachent sur le fond que constituent les repères constants d'une tonalité de référence.

Écoutons «La mer est infinie», en suivant la seule ligne vocale présentée selon la disposition des vers [Annexe 6]. On pourrait ajouter, toujours avec la même disposition des vers, une version dans laquelle on supprimerait les barres de mesure, comme le fait Robin Tait pour «Eau vivante», sixième mélodie de La Chanson d'Ève (Tait 1989, p. 196). On constate qu'à la régularité des accents indiqués par les temps forts des mesures vient se superposer une autre organisation accentuelle qui repose sur les groupements de durée ainsi que sur les mouvements mélodiques et harmoniques. J’ai porté sur le document indiqué les accents tels qu'ils m'apparaissent sans m'astreindre à suivre une théorie particulière de l'accentuation et du groupement en musique. On ne peut qu'être frappé par l'extraordinaire variété et souplesse des regroupements rythmiques au sein de la mesure. Le résultat est bien celui que dégage Robin Tait de son analyse de la mélodie «Eau vivante»:

Le contrôle de la pulsation, sans la rigidité du mètre, donne (à Fauré) toute la liberté dont il a besoin et chaque vers est transposé en musique avec une extrême sensibilité aux nuances du sens. [...] ce qui est derrière les rythmes de la ligne vocale est le désir de traduire aussi fidèlement que possible les rythmes présents dans la poésie, plutôt que de faire rentrer les mots dans un cadre métrico-rythmique préconçu (Tait 1989, p. 195).

En procédant ainsi, Fauré s'inscrivait dans une des traditions les plus anciennes de la parole chantée qui constitue sans doute un universel musical, celle dans laquelle un rythme linguistique parlando-rubato s'appuie sur une pulsation régulière : on la retrouve aussi bien dans les chants de tradition orale que dans le grégorien ou le récitatif de Monteverdi (Viret 2001, p. 388-402).

\section{Une mélodie continue ...}

Je voudrais d'abord remarquer que l'on a trop l'habitude de privilégier l'harmonie de Fauré, alors que ce n'est sans doute pas l'essentiel pour lui, et JeanMichel Nectoux est amené

à conclure à la nature essentiellement mélodique - plutôt qu'harmonique de sa pensée. Là où Debussy crée des successions d'accords inouïs, Fauré pense l'horizontale. Debussy innove dans le domaine du vocabulaire harmonique, Fauré dans celui de la syntaxe mêlant, au gré d’une fantaisie toujours contrôlée, deux domaines particuliers : le modal et le tonal (Nectoux 2008, p. 303-304).

L'insistance mise sur l'harmonie fauréenne est un effet de la conviction selon laquelle le «progrès» de la musique s'est fait à peu près exclusivement dans le 
domaine de l'harmonie. La place relativement restreinte de la mélodie dans la théorie (Nattiez 1987, p. 283-310) a connu son prolongement logique dans l'avant-garde contemporaine

qui a décrété la mort virtuelle de la mélodie comme facteur primaire de l'expérience musicale» et a ainsi conduit à des «décennies de sècheresse mélodique», durant lesquelles "la musique populaire de type commercial a été la seule source persistante et dominante d'inspiration mélodique (Ringer 2007).

La formation de Fauré, sans parler de son génie propre, l'avait familiarisé avec des musiques dans lesquelles le mélodique joue un rôle central, le grégorien et les polyphonies de la Renaissance. Comme chez ces polyphonistes, "c'est toujours le jeu des lignes qui provoque les rencontres harmoniques" (Dommel-Diény 1967, p. 66). Ce souci de la ligne permet d'établir un lien entre le sens général du mélodique opposé à l'harmonique et la place que tient dans l'œuvre de Fauré le genre même de la mélodie.

Voici comment Madame Beltrando-Patier présente le recueil :

Sur le plan de l'écriture, L'Horizon chimérique se présente comme un modèle de continuité, sans thèmes récurrents, sans découpage visible, sans structures repérables. Chaque mélodie procède librement par expansion, chaque phrase engendrant la suivante par phénomène d'amplification des intervalles, d'éloignement harmonique ou d'effets rythmiques et dynamiques. La maîtrise de l'écriture est totale et le jeu de l'instabilité amène la progression du langage de façon imperceptible, sans aucune discontinuité (Beltrando-Patier 1994, p. 229).

Il y a en fait une réutilisation à peu près littérale d'un matériau précédent dans la deuxième mélodie, «Je me suis embarqué ...» - les mesures 30 à 36 , au début de la troisième strophe, reprennent les mesures 1 à 7 -, mais c'est le seul cas dans l'ensemble du recueil. C'est pourquoi, reprenant la formule wagnérienne «cum grano salis», il ne me semble pas déplacé de parler de mélodie continue.

Sans me situer dans le cadre d'une théorie particulière de la mélodie et sans prétendre rendre compte de tous les aspects de cet "amalgame de constituants relativement hétérogènes" (Nattiez 1987, p. 287) qu'est une mélodie, je voudrais m'attacher à un seul aspect de son organisation en prenant comme exemple la première mélodie du cycle, «La mer est infinie ... » : l'enchaînement des contours et mouvements mélodiques mis en rapport avec l'organisation poétique, que je présente dans le tableau ci-joint sous forme paradigmatique [Annexe 7].

Le premier vers de la première strophe correspond à une montée par mouvement conjoint de la tonique ré à la dominante la. Le deuxième vers monte, en deux vagues et toujours par mouvement conjoint, de la dominante la à l'octave supérieure ré (la-do dièse, puis la-ré) avant de retomber, par un saut de sixte, au $f a$ bécarre inférieur. Les deux fins de vers sont soulignées, comme on l'a vu, par de brefs jeux modulants immédiatement suivis du retour à la tonique ré. Les troisième et quatrième vers présentent un nouveau contour : descente du 
ré au sol puis montée du sol au si pour le vers 3 et, pour le vers 4, montée du $s i$ au $m i$, note la plus haute de la mélodie, avant le saut d'octave descendante qui ramène au $m i$ inférieur.

La deuxième strophe repart de ce mi et les deux premiers vers reprennent un mouvement analogue à celui des deux premiers vers de la première strophe : montée du mi au la puis du la au do dièse pour revenir, par un saut de quinte, au $f a$ dièse inférieur. Le vers 7 part de ce $f a$ dièse et présente un contour ascendant ( $f a$ dièse-la) puis descendant $(l a-s o l)$, repris pour le vers 8 : saut ascendant de quinte $f a$ bécarre-do bécarre puis descente do-la.

La troisième strophe part de l'octave supérieure ré : en opposition au mouvement ascendant qui emportait les deux premiers vers des deux premières strophes et le début du vers 8 , les vers 9 et 10 présentent un même contour descendant puis ascendant : saut de sixte ré-fa dièse puis remontée disjointe $f a$ dièse-si-ré pour le vers 9, descente ré-sol puis remontée sol-si pour le vers 10. Le vers 11 reprend le contour du vers 4 avec prolongement d'une remontée au la qui conduit au balancement la-si du dernier vers.

Il me semble donc qu'indépendamment des autres dimensions du fait mélodique, Fauré a construit la ligne vocale en s'appuyant sur la structure poétique du texte qui sert de cadre à une organisation mélodique fondée sur l'enchaînement des vers et les reprises et oppositions des contours de chacun d'eux.

\section{Problèmes d'expression : le figuralisme}

Depuis la Renaissance, le figuralisme a été un élément essentiel de la musique vocale. Mais il faut distinguer plusieurs phénomènes. Il s'agit d'une part de la mise en relief d'un mot ou d'un groupe de mots par un moyen musical quelconque sans qu'il y ait l'intention de donner dans la musique un équivalent sémantique ou affectif du texte. C'est ce qui se produit dans ce que j'ai appelé soulignage par l'harmonie. Il s'agit d'autre part de figuralisme ou de madrigalisme au sens précis des termes : le musicien cherche un équivalent entre musique et sens du texte. Mais ces équivalents sont, selon les époques et les genres, plus ou moins codifiés. Il faut enfin faire une place à des schèmes caractéristiques d'un style ou d'un créateur mais qui n'ont pas nécessairement de signification déterminée.

Comparons la façon dont Debussy, Fauré, Reynaldo Hahn et Raoul Laparra ont mis en musique les deux premiers vers du poème de Verlaine «En sourdine»,

Calmes dans le demi-jour

Que les branches hautes font ...

Voici comment Arthur Wenk commente les choix opérés par les quatre musiciens :

In setting the first two lines of the text, our composers have chosen either a descending melodic line or the repetition of a single note. The former suggests a relaxing of tension suitable to the overall idea of the pœm; the latter has an incantatory effect (Wenk 1976, p. 39). 
De même, pour le vers

Et nos sens extasiés ...

il oppose «le saut extatique» choisi par Debussy et Reynaldo Hahn à la ligne descendante de Fauré qui exprimerait «the quiet languor of nature». Sans entrer dans la discussion des interprétations proposées, on peut tirer de cette comparaison la conclusion que, en dehors des époques dans lesquelles existait une rhétorique des affects, les musiciens jouissent d'une grande liberté pour mettre en musique un poème.

Y a-t-il des figuralismes dans L'Horizon chimérique? Dans sa thèse, Madame Beltrando-Patier a consacré d'importants développements aux figuralismes vocaux et instrumentaux dans les mélodies de Fauré (Beltrando-Patier 1981, p. 364-377 et p. 448-460), auxquels elle a joint des index alphabétiques de ces figuralismes (p. 388-425 et p. 512-552). Elle relève quatre figuralismes instrumentaux, qui correspondent aux figures d'accompagnement des quatre mélodies : les accords de la troisième («Diane, Séléné ...») évoquent le «calme et mystère de la nuit», les figures arpégées des trois autres évoquent respectivement le «mouvement régulier de la houle» («La mer est infinie ...»), le «rythme balancé de la vague» («Je me suis embarqué ...») et le «mouvement de l'eau» ("Vaisseaux, nous vous aurons aimés ...»). Il est cependant difficile de donner un sens trop précis à ces schèmes d'accompagnement, car ils correspondent en fait aux deux grands types qu'il a constamment utilisés. Il y a d'une part la succession régulière d'accords, présente ici dans la troisième mélodie, qui a une signification plus large que la simple évocation nocturne, puisqu'on retrouve la même texture dans d'autres mélodies tout au long de sa carrière : «ces pages toutes pénétrées de l'impassibilité lunaire - écrit Jean-Michel Nectoux à propos de "Diane, Séléné ...» - viennent clore l'incomparable ensemble des mélodies contemplatives de Fauré : Le Secret, Le Parfum impérissable, Ô Mort, poussière d'étoiles (de La Chanson d'Ève), Dans la Nymphée et Inscription sur le sable (du Jardin clos)» (Nectoux 1995, p. 210). Il en est de même pour le second type d'accompagnement, qui est en fait l'accompagnement habituel des mélodies de Fauré : il s'agit d'accords qui se présentent sous la forme d'une grande variété de figurations arpégées et qui ne se retrouvent pas seulement dans les mélodies évoquant la mer. Dans les deux cas, on le voit, le sémantisme des schèmes utilisés est extrêmement vague et ne se prête que par abus à une interprétation trop précise.

Madame Beltrando-Patier relève par ailleurs quatre figuralismes vocaux. Dans la deuxième mélodie («Je me suis embarqué ...»), l’«intonation ascendante et phrase ouverte» aux mesures 19-20 traduit l'interrogation " $\mathrm{A}$ vivre parmi vous, hélas !, avais-je une âme? », le «balancement mélodique (seconde) imitant le bercement» des mesures 26-29 accompagne le vers « Pour me bercer, comme un enfant, au creux des lames» et enfin l'« effet poignant de l'appoggiature» aux mesures 45-46 illustre la phrase «où vous ai-je laissée? ». Dans la dernière mélodie («Vaisseaux, nous vous aurons aimés ...»), le «motif ascendant de l'idéal contredit par le motif descendant de ce qui se referme» aux mesures 26-27 correspond aux derniers mots « inassouvis en moi». Si les trois premiers 
cas (interrogation, bercement, chromatisme) relèvent d'un figuralisme banal et traditionnel, il n'en est pas de même pour le dernier cas, où le saut ascendant de septième immédiatement suivi d'un saut descendant d'octave semble bien évoquer un élan suivi d'une retombée.

Je voudrais terminer par l'étude d'une figure assez fréquente dans l'œuvre mélodique de Fauré et qui appartient à la dernière catégorie indiquée plus haut, celle des schèmes récurrents qui ne semblent pas avoir de signification précise mais relèvent de la stylistique du créateur. Il s'agit du saut d'octave ascendant ou descendant, qui revient trois fois dans le recueil sous sa forme descendante : à la mesure 10 de "La mer est infinie ..." sur les deux syllabes de "comme" dans "comme des oiseaux soûls»; à la mesure 44 de «Je me suis embarqué ...» sur le groupe de mots « où vous ai-je laissée ?»; et enfin à la mesure 26 de «Vaisseaux, nous vous aurons aimés ...» sur le groupe «inassouvis en moi ». Le danger des interprétations trop étroitement inspirées par les textes apparait bien dans la diversité des sémantismes que Madame Beltrando-Patier rattache au saut d'octave descendante : «mouvement des ailes qui se replient» (BeltrandoPatier 1981, p. 389), «renversement du thème ascendant de l'amour» (p. 392), «élément lyrique de l'octave descendante» évoquant le chant (p. 395), «intervalle d'octave descendante, signifiant quelque chose qui se referme ou échappe» (p. 408), «image de la fuite et de ce qui échappe» (p. 408), «figuralisme de la voix dans une nuance piano» pour évoquer le verbe «susurrer» (p. 422). Sans exclure un sémantisme vague associé à un saut brusque qui ramène à l'octave inférieure et correspondant, comme dans la dernière mélodie du cycle, à la retombée d'un élan ou à une chute, il n'est pas interdit de voir dans la figure un procédé structural. Dans le premier cas, le saut d'octave permet de reprendre les mouvements ascendants qui caractérisent les deux premières strophes. Dans les deux autres, l'octave descendante joue le rôle de formule terminale que l'on retrouve par exemple à la fin de «En sourdine» pour illustrer les derniers mots du poème, «le rossignol chantera».

D’une façon générale, on constate donc que les figuralismes ne sont pas fréquents dans les mélodies de Fauré et qu'ils se raréfient encore dans ses dernières œuvres: «There is very little word-painting in his music. He saw no need to re-create musically those external festures of reality already expressed in the pœm» (Caballero 2001, p. 245). En 1911, dans la réponse déjà citée à l'enquête de la revue Musica, le musicien précisait:

De même dans «Il pleure dans mon cœur comme il pleut sur la ville ...» le bruit des gouttes d'eau n'est qu'un accessoire. La lamentation amoureuse et inquiète est l'essentiel. Le rôle de la musique est d'ailleurs bien celui-là : mettre en valeur le sentiment profond qui habite l'âme du poète et que les phrases sont impuissantes à rendre avec exactitude (Fauré, cité dans Nectoux 1995, p. 104).

C'est la même conception qu'il avait brièvement exprimée dans une interview de 1902 : «Je tâche surtout de dégager le sentiment général du poème, de préférence aux détails» (Aguettant 1902, cité dans Nectoux, 1995, p. 110). 
Ce refus de toute évocation trop précise me semble une caractéristique essentielle des mélodies de Fauré, qui le distingue de ses contemporains et en particulier de Debussy : dans la deuxième version de "En sourdine», c'est le chant du rossignol qui, au piano, ouvre et ferme la mélodie. Si l'on entend par impressionnisme non, comme on le fait encore trop souvent en musique, le brouillard inconsistant que condamnait Cocteau, mais l'évocation d'une nature vue à travers les reflets changeants de l'heure et de la lumière, Debussy ne mérite-t-il pas pleinement le nom d'impressionniste?

The association of accompanimental motives with moonlight and fountains in Debussy's earlier setting of Clair de lune brings to mind an idea which applies even more strongly in some of the other Verlaine songs. This is Debussy's habit of letting the piano accompaniment represent 'nature' (Wenck 1976, p. 30).

La remarque n'est-elle pas encore vraie pour l'orchestre de Pelléas.

\section{Problèmes d'interprétation : Chanter Fauré}

Pour terminer, je voudrais en venir à ce qui est l'aboutissement de cette longue chaîne qui nous a menés du poème de Jean de la Ville de Mirmont à la mélodie de Fauré : l'interprétation.

Commençons par un constat brutal mais, me semble-t-il, indiscutable : il n'est pas facile de chanter en français, car le système phonétique du français possède des caractéristiques très différentes de celles de beaucoup de langues voisines. Je rappelle trois de ces caractéristiques. 1) à la différence de ce qui se passe dans d'autres langues, l'accent en français est un accent final de groupe qui se place sur la dernière syllabe (ou avant-dernière lorsque la dernière comporte un $e$ ) du mot isolé ou du groupe de mots dans lequel le mot est inséré. Le groupe rythmique qu'il délimite est d'étendue variable et se confond avec le groupe intonatif, d'où son importance dans une bonne diction. 2) Les voyelles françaises ont une articulation tendue, dont la conséquence est qu'elles gardent la même couleur durant toute la durée de leur émission. 3) Il y a enfin cette insaisissable lettre dont on ne sait comment la nommer tellement elle a de noms $-e$ muet, $e$ caduc, $e$ féminin, $e$ instable, schwa ... - et qu'il est si difficile de prononcer correctement. Dans de nombreux contextes, on ne la prononce pas, sauf si l'on parle un français méridional ou romand, mais elle joue encore un rôle capital dans la poésie et dans le chant. Voici ce qu'en dit un poète contemporain, Jacques Réda :

L'E muet reste une pure merveille. Accordez-leur tant que vous voudrez toutes les longueurs, à moins d'idiotismes rarissimes je doute qu'il existe dans notre français moyen (ha ha) une autre voyelle ou, prosodiquement parlant, syllabe, aussi parfaitement pneumatique. Le vers roule sur cette chambre à air. Ici elle se dégonfle à vous en faire toucher la jante, ailleurs elle s'enfle au bord de l'éclatement. Du coup elle agit fatalement sur ses voisines ... (Jacques Réda, cité dans Roubaud 1978, p. 200-201). 
Et, comme le fait remarquer Jacques Roubaud, rien n'interdit de prendre le mot "pneumatique» en un second sens, philosophique : l'E muet est alors «l'élément, à la fois corporel et immatériel, agissant et invisible, par lequel se propage la poésie, celui qui : fa tremar de claritate l'are (Cavalcanti)» (Roubaud 1978, p. 201).

Il est donc toujours difficile de chanter une mélodie française, mais, lorsqu' il s'agit des mélodies de Fauré, les difficultés se multiplient : pour lui, «l'interprétation de sa musique fut un souci constant et une source d'insatisfaction continuelle» (Nectoux 2008, p. 609). Il n'aimait pas les interprètes professionnels, comme il l'écrit dans une lettre à la comtesse Greffulhe :

Et je suis sûr qu'il est beaucoup de mes mélodies, parmi celles de ces dernières années, que vous ne connaissez pas encore! Je rêve de vous les faire entendre avec des interprètes parfaits, et je n'en connais pas parmi les professionnels. Ce sont les amateurs qui me comprennent et me traduisent le mieux ... (Lettre à la comtesse Greffulhe de novembre 1902, dans Fauré 1980, p. 249)

Et il a expliqué pourquoi dans un entretien avec le journaliste Louis Aguettant :

Fauré me parle de ses interprètes, des amateurs, tels que Bagès, Mme Bardac, Melle Girette, etc., qui, dit-il, rendent sa musique mieux que les artistes. «Les artistes veulent tout 'extérioriser' : ils enlèvent à la musique son charme d'intimité». Là-dessus, couplet très senti sur l'émotion musicale éprouvée en petit comité, entre trois ou quatre fidèles, autour d'un piano. (Louis Aguettant, cité dans Nectoux 1995, p. 62)

On peut se demander si les reproches que faisait Fauré aux chanteurs professionnels de son époque ne se retrouvent pas sous la plume de Roland Barthes lorsqu'il opposait au style des chanteurs de son propre temps l'art de Charles Panzéra, qui fut, on s'en souvient, le dédicataire et le créateur de L'Horizon chimérique. Barthes en a fait l'éloge à plusieurs reprises : dans un des textes de Mythologies intitulé «Lart vocal bourgeois» (Barthes 1957), dans un article paru en 1972 dans le numéro 9 de la revue Musique en jeu, "Le grain de la voix» (Barthes 1972) et enfin dans une conférence prononcée à Rome en 1977, «La musique, la voix, la langue» (Barthes 1977). Il avait pris des leçons de chant avec lui et affirmait qu'il avait « un rapport amoureux» à sa voix (Barthes (1977) 1994, p. 880). Charles Panzéra était pour lui l'antithèse de chanteurs de mélodies comme Gérard Souzay, à qui il reprochait, lorsqu'il chantait Fauré, son «esprit mélodramatique» qui lui faisait multiplier les gestes d'expressivité emphatique en pratiquant le rubato ou l'accentuation des consonnes doubles pour souligner l'intensité d'une «tristesse affreuse» (Barthes (1957) 1993, p. 667). Panzéra au contraire chantait «à voix nue», respectant la pureté des voyelles comme l'«âpreté» des nasales, roulant le $r$ avec discrétion et donnant aux consonnes une "patine» qui en faisait le simple support des voyelles. L'essentiel pour lui était de réaliser l'harmonie «de la ligne du sens (la phrase) et de la ligne de la musique (le phrasé)» (Barthes (1977) 1994, p. 883). Et Barthes souligne l'extrême respect dont témoignait le chanteur à l'égard de la phonétique et de la prosodie 
du français : «Si je veux savoir ce qu'est la langue française, c'est à l'art de Panzéra que je m'adresse : une pensée extrême y règle la prosodie de l'énonciation et l'économie phonique de notre langue» (Barthes (1972) 1994, p. 1439).

Je me demande si l'une des interprétations récentes les plus fidèles à l'esprit de Fauré ne serait pas celle qu'a réalisée, à l'âge de soixante et onze ans, un autre chanteur suisse, Hugues Cuenod, car on y retrouve les qualités que recherchait le musicien : respect de la ligne vocale, tempo sans faiblesse, voix claire et agile dans le registre supérieur, ton modeste sans surinterprétation, parlé-chanté qui unit chant et diction (Nectoux 1999, p. 389-395). À l'occasion de son cent cinquième anniversaire, le vingt-six juin 2007, Hugues Cuenod a déclaré à Associated Press : "J'ai toujours eu une petite voix. Avec elle, j’ai toujours voulu chanter de petites choses dans de grands théâtres, plutôt que de grandes choses dans de petits théâtres ... Je n'ai jamais hurlé ou crié». C’est bien la raison pour laquelle je crois que Fauré l'aurait aimé ....

\section{AnNeX 1}

\section{L'Horizon chimérique I}

Je suis né dans un port et depuis mon enfance J'ai vu passer par là des pays bien divers.

Attentif à la brise et toujours en partance.

Mon cœur n’a jamais pris le chemin de la mer.

Je connais tous les noms des agrès et des mâts, La nostalgie et les jurons des capitaines,

Le tonnage et le fret des vaisseaux qui reviennent

Et le sort des vaisseaux qui ne reviendront pas.

Je présume le temps qu'il fera dès l'aurore,

La vitesse du vent et l'orage certain,

Car mon âme est un peu celle des sémaphores,

Des balises, leurs sœurs, et des phares éteints.

Les ports ont un parfum dangereux pour les hommes

Et si mon cœur est faible et las devant l'effort, S'il préfère dormir dans de lointains arômes, Mon Dieu, vous le vouliez, je suis né dans un port.

II

Par l'appel souriant de sa claire étendue Et les feux agités de ses miroirs dansants

La mer, magicienne éblouissante et nue,

Éveille aux grands espoirs les cœurs adolescents.

Pour tenter de la fuir leur effort est stérile;

Les moins aventureux deviennent ses amants, $\mathrm{Et}$, dès lors, un regret éternel les exile,

Car l'on ne guérit point de ses embrassements.

C'est elle, la première, en ouvrant sa ceinture

D'écume, qui m'offrit son amour dangereux 
Dont mon âme a gardé pour toujours la brûlure Et dont j'ai conservé le reflet dans mes yeux.

III

Quel caprice insensé de tes désirs nomades, Mon cœur, ô toi mon cœur qui devrais être las, Te fait encore ouvrir la voile au vent des rades Où ton plus fol amour naguère appareilla?

Tu sais bien qu'au lointain des mers aventureuses Il n'est point de pays qui vaille ton essor, Et que l'horizon morne où la vague se creuse N'a d'autres pèlerins que les oiseaux du Nord.

Tu ne trouverais plus à la fin de ta course L'île vierge à laquelle aspirent tes ennuis. Des pirates en ont empoisonné les sources. Incendié les bois et dévoré les fruits.

Voyageur, voyageur, abandonne aux orages Ceux qui n'ont pas connu l'amertume des eaux. Sache borner ton rêve à suivre du rivage L'éphémère sillon que tracent les vaisseaux.

IV

Le ciel incandescent d'un million d'étoiles Palpite sur mon front d'enfant extasié.

Le feu glacé des nuits s'infuse dans mes mœlles Et je me sens grandir comme un divin brasier.

Les parfums de juillet brûlent dans le silence D'une trop vaste et trop puissante volupté.

Vers l'azur ébloui, comme un oiseau, s'élance, En des battements fous, mon cœur ivre d'été.

Que m'importe, à présent, que la terre soit ronde Et que l'homme y demeure à jamais sans espoir? Oui, j'ai compris pourquoi l'on a créé le monde; C'était pour mon plaisir exubérant d'un soir!

\section{$\mathrm{V}$}

Vaisseaux, nous vous aurons aimés en pure perte; Le dernier de vous tous est parti sur la mer. Le couchant emporta tant de voiles ouvertes Que ce port et mon cœur sont à jamais déserts.

La mer vous a rendus à votre destinée, $\mathrm{Au}$-delà du rivage où s'arrêtent nos pas. Nous ne pouvions garder vos âmes enchaînées; Il vous faut des lointains que je ne connais pas.

Je suis de ceux dont les désirs sont sur la terre. Le souffle qui vous grise emplit mon cœur d'effroi, Mais votre appel, au fond des soirs, me désespère, 
Car j’ai de grands départs inassouvis en moi.

VI

Vaisseaux des ports, steamers à l'ancre, j'ai compris

Le cri plaintif de vos sirènes dans les rades.

Sur votre proue et dans mes yeux il est écrit

Que l'ennui restera notre vieux camarade.

Vous le porterez loin sous de plus beaux soleils

Et vous le bercerez de l'équateur au pôle.

Il sera près de moi, toujours. Dès mon réveil, Je sentirai peser sa main sur mon épaule.

Assis à votre bord, éternel passager,

Il se réfléchira sur les mers transparentes,

Dans le déroulement d'une fumée errante,

Parmi les pavillons et les oiseaux légers,

L'ennui, seul confident de nos âmes parentes.

\section{ANNEX 2}

VII

Le vent de l'océan siffle à travers les portes

Et secoue au jardin les arbres effeuillés.

La voix qui vient des mers lointaines et plus forte

Que le bruit de mon cœur qui s'attarde à veiller.

Ô souffle large dont s'emplissent les voilures,

Souffle humide d'embrun et brûlant de salure,

Ô souffle qui grandis et recourbes les flots

Et chasses la fumée, au loin, des paquebots!

Tu disperses aussi mes secrètes pensées,

Et détournes mon cœur de ses douleurs passées.

L'imaginaire mal que je croyais en moi

N'ose plus s'avouer auprès de ce vent froid

Qui creuse dans la mer et tourmente les bois.

VIII

Toi qui le connais mal et que les autres n'aiment

Qu'en de vains ornements qui ne sont pas toi-même,

Afin que ta beauté natale ne se fane,

Mon âme, pare-toi comme une courtisane.

Lorsque reviendra l'ombre et que tu seras nue,

Seule devant la nuit qui t'aura reconnue

Et loin de la cité dont la rumeur t'offense,

Tu te retrouveras pareille à ton enfance,

Mon âme, sœur des soirs, amante du silence.

IX

Ô la pluie! Ô le vent! Ô les vieilles années!

Dernier baiser furtif d'une saison qui meurt

Et premiers feux de bois au fond des cheminées! 
L'hiver est installé, sans sursis, dans mon cœur.

Vous voilà de retour, mes pâles bien-aimées, Heures de solitude et de morne labeur, Fidèles aux lueurs des lampes allumées Parmi le calme oubli de l'humaine rumeur.

Un instant, j'ai pensé que la plus fière joie Eût été de m'enfuir, comme un aigle s'éploie, $\mathrm{Au}$ lointain rouge encore des soleils révolus.

Et j'enviais le sort des oiseaux de passage. Mais mon âme s'apaise et redevient plus sage, Songeant que votre amour ne me quittera plus.

$\mathrm{X}$

Mon désir a suivi la route des steamers Qui labourent les flots d'une proue obstinée Dans leur hâte d'Atteindre à l'horizon des mers Où ne persiste d'eux qu'une vaine fumée.

Longtemps il s'attarda, compagnon des voiliers Indolents et déchus, qu'un souffle d'aventure Ranime par instants en faisant osciller Le fragile appareil de leur haute mâture.

Mais la nuit vient trop vite et ne me laisse plus Pour consoler encor mon âme à jamais lasse, Que les cris de dispute et les chants éperdus Des marins enivrés dans les auberges basses.

XI

Diane, Séléné, lune de beau métal, Qui reflète vers nous, par ta face déserte, Dans l'immortel ennui du calme sidéral, Le regret d'un soleil dont nous pleurons la perte,

Ô lune, je t'en veux de ta limpidité Injurieuse au trouble vain des pauvres âmes, Et mon cœur, toujours las et toujours gité, Aspire vers la paix de ta nocturne flamme.

XII

Novembres pluvieux, tristes au bord des fleuves Qui ne reflètent plus le mirage mouvant Des nuages au ciel, des arbres dans le vent, Ni l'aveuglant soleil dont nos âmes sont veuves,

Faut-il que notre exil sous vos froides clartés $\mathrm{Ne}$ conserve d'espoir que le peu que nous laisse Le cri des trains de nuit qui sifflent leur détresse, Quand les rêves sont morts dans les grandes cités?

XIII

La mer est infinie et mes rêves sont fous. 
La mer chante au soleil en battant les falaises

Et mes rêves légers ne se sentent plus d'aise

De danser sur la mer comme des oiseaux soûls.

Le vaste mouvement des vagues les emporte, La brise les agite et les roule en ses plis; Jouant dans le sillage, ils feront une escorte Aux vaisseaux que mon cœur dans leur fuite a suivis.

Ivres d'air et de sel et brûlés par l'écume De la mer qui console et qui lave des pleurs, Ils connaîtront le large et sa bonne amertume; Les goélands perdus les prendront pour des leurs.

XIV

Je me suis embarqué sur un vaisseau qui danse Et roule bord sur bord et tangue et se balance. Mes pieds ont oublié la terre et ses chemins; Les vagues souples m'ont appris d'autres cadences Plus belles que le rythme las des chants humains.

À vivre parmi vous, hélas! avais-je une âme? Mes frères, j'ai souffert sur tous vos continents. Je ne veux que la mer, je ne veux que le vent Pour me bercer, comme un enfant, au creux des lames.

Hors du port qui n'est plus qu'une image effacée, Les larmes du départ ne brûlent plus mes yeux. Je ne me souviens pas de mes derniers adieux... Ô ma peine, ma peine, où vous ai-je laissée?

Voilà! Je suis parti plus loin que les Antilles, Vers des pays nouveaux, lumineux et subtils. Je n'emporte avec moi, pour toute pacotille, Que mon cœur... Mais les sauvages, en voudront-ils? 


\section{Annex 3}

Lydia

Lydia, sur tes roses joues, Et sur ton col frais et plus blanc Que le lait, roule étincelant L'or fluide que tu dénoues.

Le jour qui lui est le meilleur ; Oublions l'éternelle tombe. Laisse tes baisers de colombe Chanter sur tes lèvres en fleur.

Un lys caché répand sans cesse Une odeur divine en ton sein ; Les délices, comme un essaim, Sortent de toi, jeune Déesse.

Je t'aime et meurs, ô mes amours ! Mon âme en baisers m'est ravie. O Lydia, rends-moi la vie, Que je puisse mourir toujours!

Leconte de Lisle
Lydia

Lydia, sur tes roses joues

Et sur ton col frais et si blanc,

Roule étincelant

L'or fluide que tu dénoues ;

Le jour qui lui est le meilleur, Oublions l'éternelle tombe.

Laisse tes baisers, tes baisers de colombe Chanter sur ta lèvre en fleur, sur ta lèvre en fleur.

Un lys caché répand sans cesse Une odeur divine en ton sein ; Les délices comme un essaim Sortent de toi, jeune Déesse.

Je t'aime et meurs, ô mes amours. Mon âme en baisers m'est ravie! O Lydia, rends-moi la vie, Que je puisse mourir toujours.

Fauré

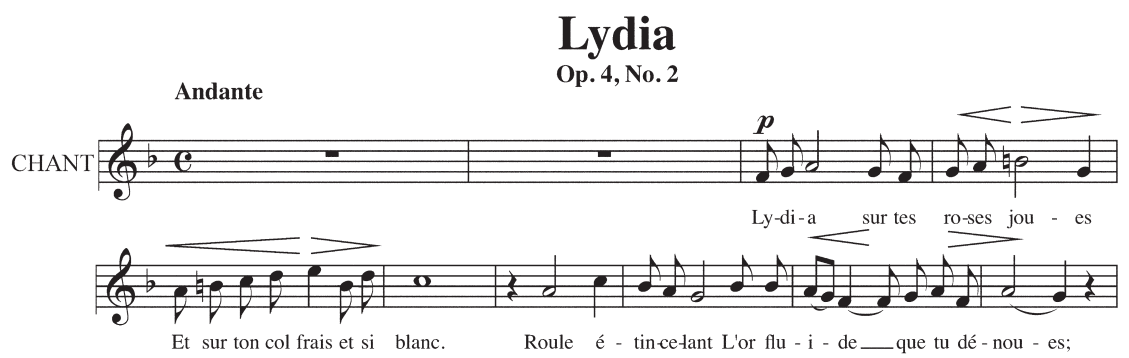

ANNeX 4

[XIII] $\Rightarrow$ I

La mer est infinie et mes rêves sont fous.

La mer chante au soleil en battant les falaises

Et mes rêves légers ne se sentent plus d'aise

De danser sur la mer comme des oiseaux soûls.

Le vaste mouvement des vagues les emporte,

La brise les agite et les roule en ses plis;

Jouant dans le sillage, ils feront une escorte

Aux vaisseaux que mon cœur dans leur fuite a suivis.

Ivres d'air et de sel et brûlés par l'écume 
De la mer qui console et qui lave des pleurs, Ils connaîtront le large et sa bonne amertume;

Les goélands perdus les prendront pour des leurs.

[XIV] $\Rightarrow$ II

Je me suis embarqué sur un vaisseau qui danse Et roule bord sur bord et tangue et se balance.

Mes pieds ont oublié la terre et ses chemins;

Les vagues souples m'ont appris d'autres cadences

Plus belles que le rythme las des chants humains.

À vivre parmi vous, hélas! avais-je une âme?

Mes frères, j'ai souffert sur tous vos continents.

Je ne veux que la mer, je ne veux que le vent

Pour me bercer, comme un enfant, au creux des lames.

Hors du port qui n'est plus qu'une image effacée,

Les larmes du départ ne brûlent plus mes yeux.

Je ne me souviens pas de mes derniers adieux...

Ô ma peine, ma peine, où vous ai-je laissée?

[Voilà! Je suis parti plus loin que les Antilles, Vers des pays nouveaux, lumineux et subtils. Je n'emporte avec moi, pour toute pacotille, Que mon cœur... Mais les sauvages, en voudront-ils?]

[XI] $\Rightarrow$ III

Diane, Séléné, lune de beau métal,

Qui reflète vers nous, par ta face déserte,

Dans l'immortel ennui du calme sidéral,

Le regret d'un soleil dont nous pleurons la perte,

Ô lune, je t'en veux de ta limpidité

Injurieuse au trouble vain des pauvres âmes,

Et mon cœur, toujours las et toujours gité,

Aspire vers la paix de ta nocturne flamme.

[V] $\Rightarrow$ IV

Vaisseaux, nous vous aurons aimés en pure perte;

Le dernier de vous tous est parti sur la mer.

Le couchant emporta tant de voiles ouvertes

Que ce port et mon cœur sont à jamais déserts.

La mer vous a rendus à votre destinée,

$\mathrm{Au}$-delà du rivage où s'arrêtent nos pas.

Nous ne pouvions garder vos âmes enchaînées;

Il vous faut des lointains que je ne connais pas.

Je suis de ceux dont les désirs sont sur la terre.

Le souffle qui vous grise emplit mon cœur d'effroi,

Mais votre appel, au fond des soirs, me désespère,

Car j'ai de grands départs inassouvis en moi. 


\section{Annex 5}
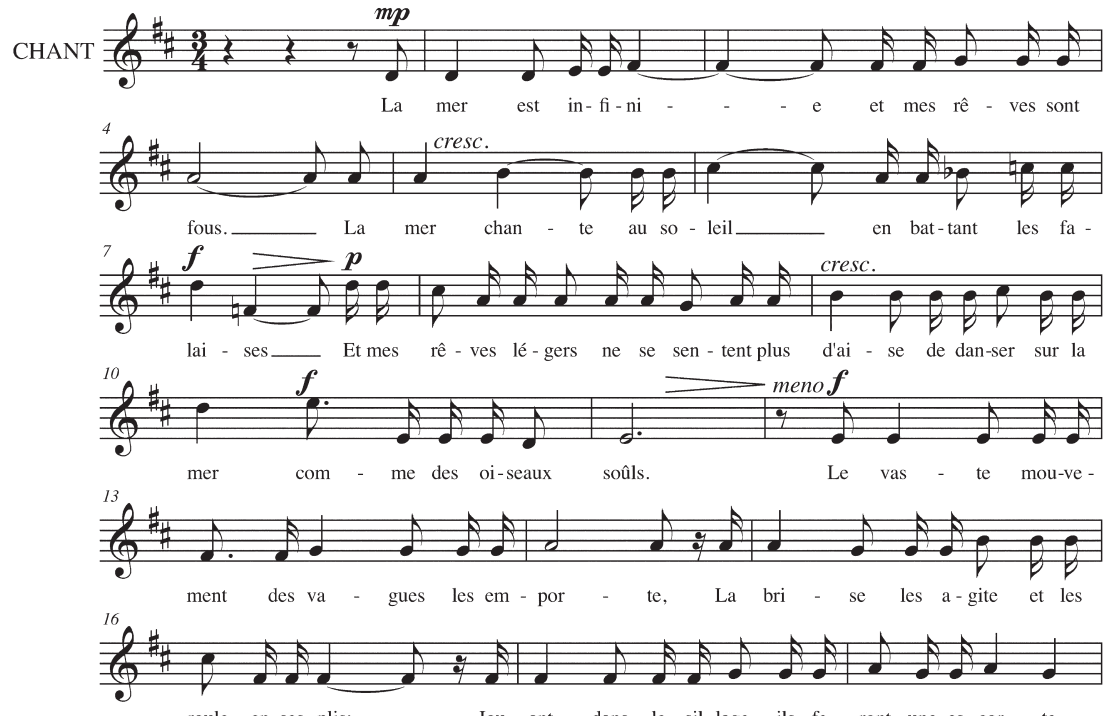

roule en ses plis; __ Jou - ant dans le sil-lage, ils fe - ront une es-cor - te
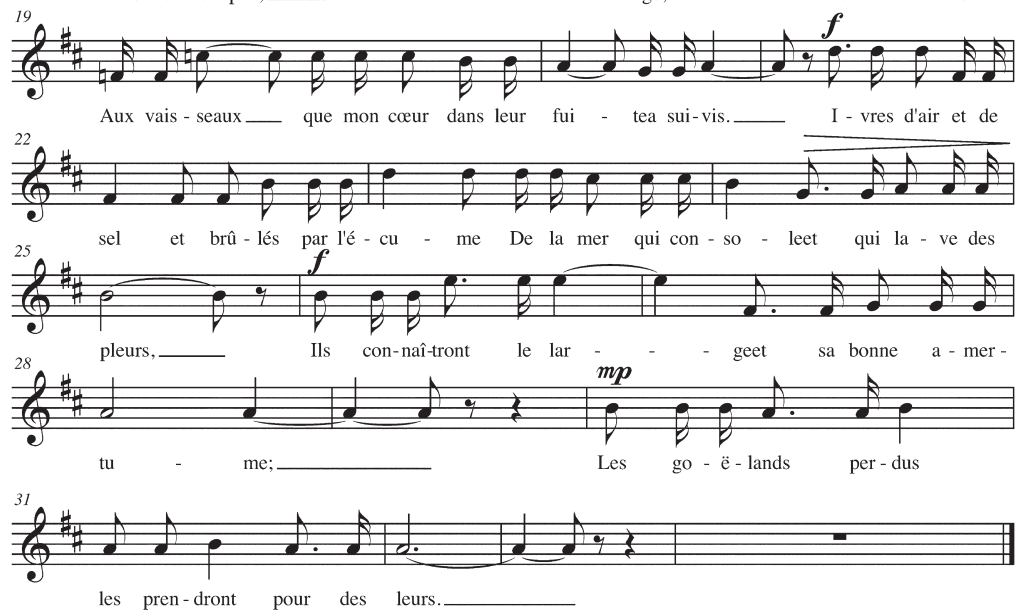


\section{Annex 6}

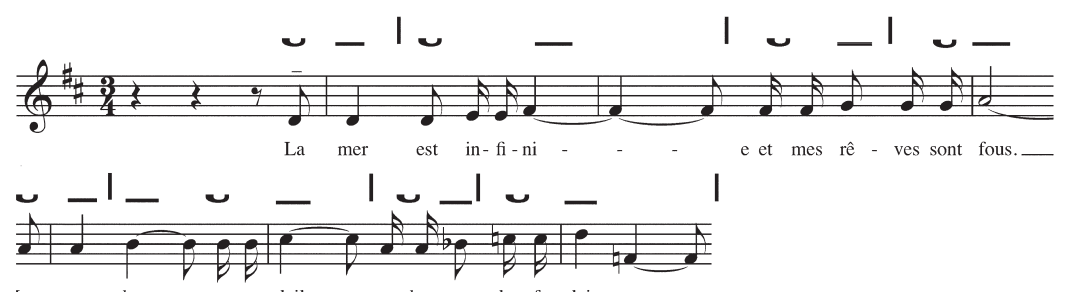

La mer chan - teau so - leil___ en bat-tant les fa - lai - ses__

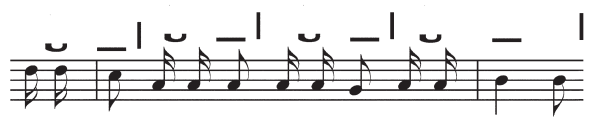

Et mes rê - ves lé - gers ne se sen - tent plus d'ai - se

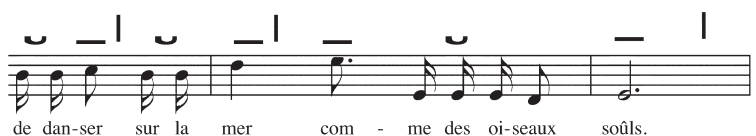

de dan-ser sur la mer com - me des oi-seaux soûls.
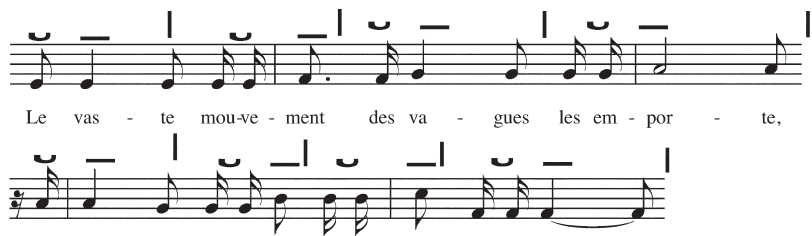

La bri - se les a-gite et les roule en ses plis;
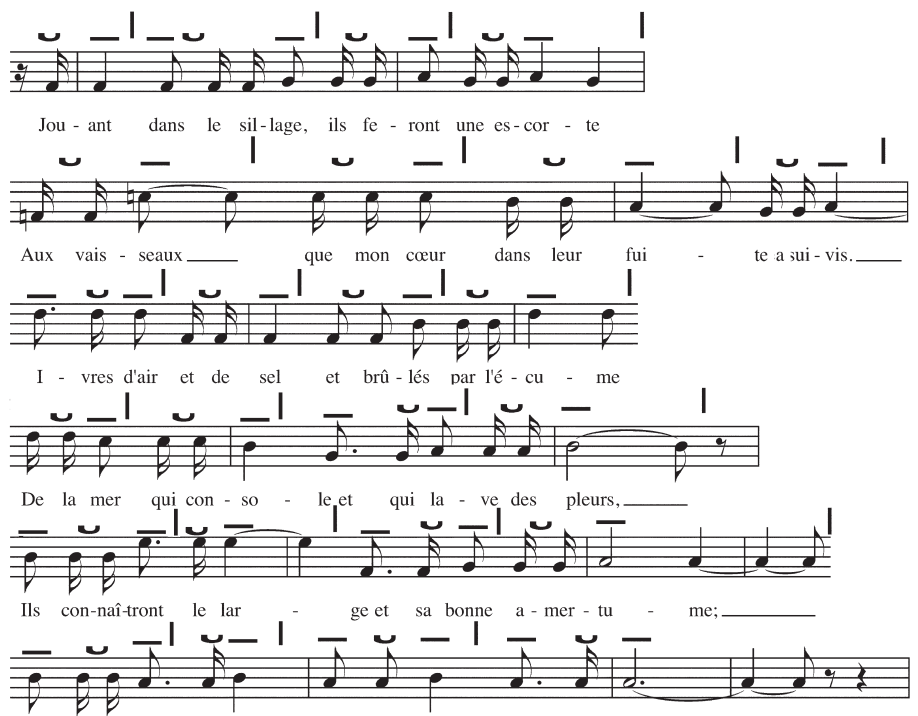

Les go-ë-lands per-dus les pren-dront pour des leurs. 

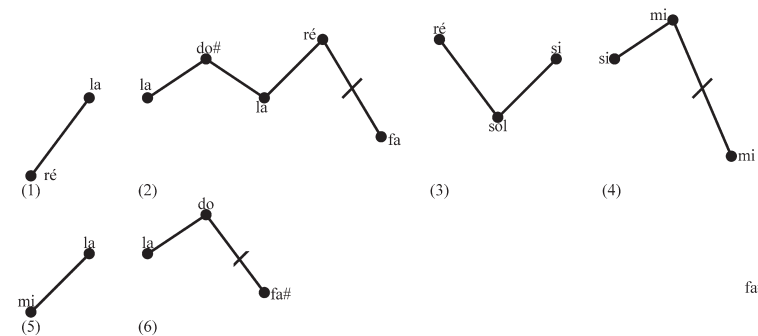

(3)

(4)

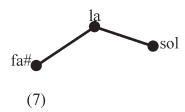

X: saut $\geqslant$ quinte
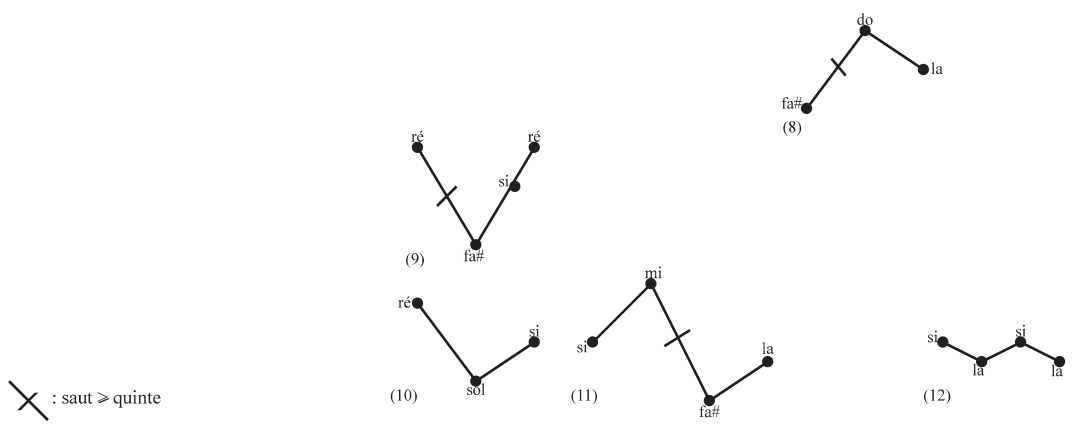

\section{RÉFÉRENCES}

Barthes, Roland. 1957. «L'art vocal bourgeois». Mythologies. Paris : Seuil. Repris dans Euvres complètes 1942-1965, vol. 1, sous la dir. de É. Marty, 666-668. Paris : Seuil, 1993.

. 1972. «Le grain de la voix». Musiques en jeu, $\mathrm{n}^{\circ}$ 9. Repris dans Euvres complètes 1966-1973, vol. 2, 1436-1442. Paris : Seuil, 1994.

__ 1977. «La musica, la voce, il languaggio». Nuova rivista musicale italiana, 20, $\mathrm{n}^{\mathrm{0}}$ 3. 9 (Publ. orig. «La musique, la voix, la langue» repris dans Euvres complètes 1974-1980, vol. 3 sous la dir. de É. Marty, 880-884. Paris : Seuil, 1994)

Baudelaire, Charles. 1975. "Chacun sa chimère». Dans Le Spleen de Paris, Euvres complètes, vol. 1, 282-283. Paris : Gallimard

Beaudouin, Valérie. 2002. Mètre et rythme du vers classique : Corneille et Racine. Paris : Honoré Champion.

Beaufils, Marcel. [1954] 1994. Musique du son, musique du verbe. Paris : Klincksieck.

Beltrando-Patier, Marie-Claire. 1981. Les Mélodies de G. Fauré, Service de reproduction des thèses, Université de Lille III.

___ 1994 "Gabriel Fauré». Guide de la mélodie et du lied, sous la dir de Brigitte François-Sappey et Gilles Cantagrel, 211-230. Paris : Fayard.

Bettens, Olivier. 2008. "Chronique d'un éveil prosodique (1567-1643)». Chantez-vous français? http://virga.org/cvf/chronique.php 
Billy, Dominique. 2003. "Accent et mètre dans le vers français. Á propos d'un livre de R. Pensom », Revue de linguistique romane $\mathrm{n}^{0} 67$ : 365-403.

Bourguès, Lucien, et Alexandre Denéréaz. 1921. La Musique et la vie intérieure. Paris / Lausanne : Félix Alcan / Georges Bridel.

Büsser, Henri. 1961. Gounod. Paris : EISE.

Caballero, Carlo. 2001. Fauré and French Musical Aesthetics. Cambridge, New York : Cambridge University Press.

Carton, Fernand. 1979. Introduction à la phonétique du français. Paris : Bordas.

Chaurand, Jacques. 1991. «La découverte de l'accent tonique français». Verbum $14, \mathrm{n}^{\circ} 2-4: 217-226$.

Cornulier de, Benoît. 1982. Théorie de vers : Rimbaud, Verlaine, Mallarmé. Paris : Seuil.

—1995. Art poétique: notions et problèmes de métrique. Lyon : Presses universitaires de Lyon.

Dalmonte, Rossana. 2004. «Musique, texte, poésie». Musiques. Une encyclopédie pour le XXI siècle, «2. Les savoirs musicaux», sous la dir. de Jean-Jacques Nattiez, 233-255. Arles-Paris : Actes Sud/Cité de la musique.

Deloffre, Frédéric. 1973. Le Vers français. Paris : SEDES.

Dommel-Diény, Amy. 1967. L'analyse harmonique en exemples de J.-S. Bach à Debussy, fascicule 13 : Fauré. Neuchâtel : Delachaux et Niestlé.

Elwert, W. Theodor. 1965. Traité de versification française des origines à nos jours. Paris : Klincksieck.

Faure, Michel et Vincent Vivès. 200o. Histoire et poétique de la mélodie française. Paris : CNRS Éditions

Fauré, Gabriel. 1980. Correspondance, présentée et annotée par Jean-Michel Nectoux. Paris : Flammarion.

Fortassier, Pierre. 1955. «Rythme verbal et rythme musical : à propos de la prosodie de Gabriel Fauré». Mélanges d'histoire et d'esthétique musicale offerts à Paul-Marie Masson, vol. 1, 29-37. Paris : Richard-Massé.

_. 1960 : "Verlaine, la musique et les musiciens», Cahiers de l'Association internationale des études françaises, $\mathrm{n}^{0} 12: 29-37$.

—. 1976 : «Le rythme dans les mélodies de Gabriel Fauré», Revue de musicologie $62, \mathrm{n}^{\circ} 2: 257-274$.

François-Sappey, Brigitte et Gilles Cantagrel. 1994. Guide de la mélodie et du lied. Paris : Fayard.

Gasparov, M. L.1996. A History of European Versification. Oxford : Clarendon Press.

Gouvard, Jean-Michel. 1999. La Versification. Paris : PUF.

2000. Critique du vers. Paris : Honoré Champion.

Gut, Serge.1994. Aspects du lied romantique allemand. Arles : Actes Sud.

His, Isabelle. 1998. "Évolution du souci prosodique dans la mise en musique du français de la seconde moitié du XVI ${ }^{\mathrm{e}}$ siècle : le cas de Claude Le Jeune». Dans À haute voix. Diction et prononciation aux XVI et XVII siècles, sous la dir. de Olivia Rosenthal, Actes du colloque de Rennes (1996), 87-102. Paris : Klincksieck. 
1993. "Claude Lejeune et le rythme prosodique : la mutation des années 1570 ». Revue de musicologie 79, $\mathrm{n}^{\circ} 2$ : 201-226.

Kœchlin, Charles, 1925 : «La mélodie». Cinquante ans de musique française (1874-1925), vol. 2, sous la direction de Ladislas Rohozinski, 1-62. Paris : Les Editions Musicales de la Librairie de France.

-1927. G. Fauré. Paris : Alcan.

Lacheret-Dujour, Anne et Frédéric Beaugendre. 1999. La Prosodie du français. Paris : CNRS Éditions.

Lacouture, Jean. 2004. La Rumeur d'Aquitaine: des eaux, des arbres et puis des mots. Paris : Stock.

Laurent, Alain. 1994. L'individualisme méthodologique. Que sais-je?, no 2906. Paris : Presses universitaires de France.

Laurenti, Jean-Noël. 2008. "Approche des problèmes accentuels dans la prosodie de Cadmus et Hermione (Lully), Armide (Lully) et Médée (Charpentier) ». Archives électroniques du GRIMAS (Groupe de Recherche Interdisciplinaire sur la Musique et les Arts du Spectacle aux XVII et XVIII siècles, dir. R. Legrand), consultable sur le site des Patrimoines musicaux, http:// pm.paris4.sorbonne.fr/main/activites/ grimas.htm.

La Ville de Mirmont, Jean de. 1920. L’Horizon chimérique, Poèmes ornés de bois gravés de Léon Dusouchet. Paris : Société Littéraire de France.

—_ 1992 : Euvres complètes. Introduction et présentation générale par Michel Suffran, préface de François Mauriac. Seyssel : Editions Champ Vallon.

Leconte de Lisle, Charles Marie Leconte dit. 1977. Poèmes antiques. Paris : Les Belles Lettres.

Léon, Pierre Roger. 1966. Prononciation du français standard : aide-mémoire d'orthoépie à l'usage des étudiants étrangers. Montréal : Didier.

Le Roux, François et Romain Raynaldy. 2004. Le Chant intime : de l'interprétation de la mélodie française. Paris : Fayard.

Lote, Georges. 1949-1996. Histoire du vers français. Paris : Boivin (tomes 1-3), Aix en Provence : Publications de l'Université de Provence (tomes 4-9).

Mallarmé, Stéphane. 1897. «Crise de vers». Divagations. Paris : Fasquelle.

Marmontel, Jean-François. [1787] 1879. Eléments de littérature. 3 vol. Paris : Firmin-Didot.

Molino, Jean. 2009. Le Singe musicien. Sémiologie et anthropologie de la musique, 269-275. Arles: Actes Sud.

__ 2002. "La pœsia cantata. Alcuni problemi teorici». Dans Sul verso cantato. La poesia orale in una prospettiva etnomusicologica, sous la dir. de M. Agamennone et F. Giannattasio, 17-33. Padoue : Il Poligrafo. (Publ. orig. dans le Singe musicien, 249-261. Arles : Actes Sud, 2009)

. 2006 : «Pour une autre histoire de la musique. Les réécritures de l'histoire dans la musique du XX $\mathrm{X}^{\mathrm{e}}$ siècle». Musiques. Une Encyclopédie pour le $X X I^{e}$ siècle, "4. Histoire des musiques européennes", sous la dir. de JeanJacques Nattiez, 1386-1440. Arles-Paris : Actes Sud/Cité de la Musique.

Molino, Jean, et Joëlle Gardes-Tamine. 1988. Introduction à l'analyse de la poésie. vol. 2 De la strophe à l'organisation du poème. Paris : PUF. 
1992. Introduction à l'analyse de la poésie. vol. 1. Vers et figures. Paris : PUF.

Mounin, Georges. 1969. La Communication poétique, précédé de Avez-vous lu Char? Paris : Gallimard.

Nattiez, Jean-Jacques. 1987. Musicologie générale et sémiologie. Paris: Bourgois. . 2007. Profession musicologue, 31. Montréal : Presses de l'Université de Montréal.

Nectoux, Jean- Michel. 1995. Fauré. Paris, Seuil, Collection Solfèges. (Publ. orig. Paris : Seuil, 1972)

—. 1996 : «Voix, style, vocalité : les premiers interprètes de Fauré». D’un opéra, l'autre, hommage à Jean Mongrédien, sous la dir. de Jean, Gribenski, 133-140. Paris : Presses de l’Université de Paris-Sorbonne.

_.1999. «Fauré : Voice, Style and Vocality ». Regarding Fauré sous la dir. de Tom Gordon, 370-402. Amsterdam : Gordon and Breach.

-2008. Gabriel Fauré. Les voix du clair-obscur. Paris : Fayard. (Publ. orig. Paris : Flammarion, 1990.)

Nettl, Bruno. 1973. Folk and Traditional Music of western Continents (with chapters on Latin America by Gérard Béhague). Englewood Cliffs, N.J. : Prentice-Hall.

Noske, Frits. 1970. La Mélodie française de Berlioz à Duparc : essai de critique historique. New York : Dover. (Publ. orig. Paris-Amsterdam : PUF/NorthHolland Publishing Company, 1954.)

Orledge, Robert. 1979. Gabriel Fauré. London : Eulenburg. (Édition révisée en 1983)

Ouvrard, Jean-Pierre. 1981. «Les jeux du mètre et du sens dans la chanson polyphonique française du XVI ${ }^{\mathrm{e}}$ siècle (1528-1550) ». Revue de musicologie 67, $\mathrm{n}^{\mathrm{o}} 1: 5-34$.

Panzéra, Charles. 1964. 50 mélodies françaises. Bruxelles : Schott Frères.

Pensom, Roger. 200o. Accent and metre in French. $2^{\mathrm{e}}$ éd. Bern-New York : Peter Lang. (Publ. orig. Bern : Peter Lang, 1998.)

Pich, Edgard. 1977. «Principes et méthodes». Dans Leconte de Lisle, 7-33. Paris : Les Belles Lettres.

Popper, Karl. 1957. The Poverty of Historicism. Londres : Routledge and Paul Kegan. Éd. fr. Misère de l'historicisme, 145-157. Paris : Plon, 1956 (sic.)

-1972. Objective Knowledge, 178-179. Oxford: Oxford University Press.

Proust, Marcel. 1987. Á la recherche du temps perdu. Bibliothèque de la Pléiade, vol. 1. Paris : Gallimard.

Quicherat, Louis. 1838. Petit Traité de versification française. Paris : Hachette.

-1850: Traité de versification française, Paris, Hachette.

Rameau, Jean-Philippe. [1754] 1980. "Observations sur notre instinct pour la musique et sur son principe». Dans Musique Raisonnée, textes choisis, présentés et commentés par Catherine Kinztler et Jean-Claude Malgloire. Paris : Stock.

Ravel, Maurice. 1922. «Les Mélodies de Gabriel Fauré ». La Revue musicale $\mathrm{n}^{\circ} 11$ ( $1^{\mathrm{er}}$ octobre 1922) : 22-27. 
Ringer, Alexander L. 2007. «Melody, $\$ 11$ : Absolute melody?». Grove Music Online, www. oxfordmusiconline.com.

Roubaud, Jacques. 1978. La Vieillesse d'Alexandre. Paris : Maspero.

Rousseau, Jean-Jacques. [1753]1995. Écrits sur la musique. Paris : Gallimard.

Ruwet, Nicolas. 1972. Langage, musique, poésie. Paris : Seuil.

Saint-Saëns, Camille. 1885. Harmonie et mélodie, $2^{\mathrm{e}}$ éd. Paris : Calmann-Lévy.

Schœnberg, Arnold. 1984. Style and Idea. Berkeley and Los Angeles: University of California Press.

Scoppa, Antonio. 1811. Les Vrais Principes de la versification développés par un examen comparatif entre la langue italienne et la française. 3 vol. Paris : Courcier,

Souriau, Etienne. 1969. La Correspondance des arts. Paris : Flammarion.

Suffran, Michel. 1968. Jean de la Ville de Mirmont. Collection Poètes d'aujourd'hui. Paris : Seghers.

Tait, Robin. 1989. The Musical Language of Gabriel Fauré. New York: Garland. Thieme, Hugo Paul. 1916. Essai sur l'histoire du vers français. Paris : Champion Valéry, Paul. [1926] 1960. «De la diction des vers». Euvres II, Bibliothèque de la Pléiade, 1253- 1259. Paris : Gallimard.

Viret, Jacques. 2001. Le Chant grégorien et la tradition grégorienne. Lausanne : L'Âge d'Homme.

Wenk, Arthur B.1976. Claude Debussy and the Pœets. Berkeley and Los Angeles : University of California Press.

\section{RÉSUMÉ}

Dans cet article, l'auteur retrace la genèse de L'Horizon chimérique de Fauré, depuis sa première rencontre entre le musicien et le poète jusqu'au terme de la mise en musique et finalement le problème de l'exécution. Il attache une importance particulière aux caractéristiques formelles du poème (prosodie, rythme, métrique) et essaie de montrer l'importance qu'elles revêtent tout au long du parcours créateur jusqu'aux plus petits détails de la mise en musique.

\section{ABSTRACT}

In this article, the author follows the genesis of Fauré's L'Horizon chimérique from the first encounter between musician and pœet to the completion of the musical setting and finally to problems of performance. He pays particular attention to the formal characteristics of a pœm (prosody, rhythm, metrics) and tries to show their importance all the way to the smallest details of the musical setting. 